\title{
MiR-16-5p is frequently down-regulated in astrocytic gliomas and modulates glioma cell proliferation, apoptosis, and response to cytotoxic therapy
}

Krell, Anneliese ; Wolter, Marietta ; Stojcheva, Nina ; Hertler, Caroline ; Liesenberg, Franziska ; Zapatka, Marc ; Weller, Michael ; Malzkorn, Bastian ; Reifenberger, Guido

\begin{abstract}
AIMS Aberrant expression of microRNAs (miRNAs) is frequent in various cancers including gliomas. We aimed to characterize the role of miR-16-5p as a candidate tumour suppressor miRNA in gliomas. METHODS Real-time PCR-based approaches were used for miRNA and mRNA expression profiling of glioma and non-neoplastic brain tissues as well as glioma cell lines. Protein levels were determined by Western blotting. In vitro analyses were performed following overexpression of miR16-5p, trichostatin A treatment, and siRNA-mediated knock-down of HDAC3 in glioma cells. Effects of miR-16-5p on glioma cell viability, apoptosis and response to irradiation and temozolomide were assessed. RESULTS Expression of miR-16-5p was reduced relative to control brain tissue in isocitrate dehydrogenase (IDH)-mutant astrocytomas of World Health Organization (WHO) grades II, III, and IV, and a subset of IDH-wildtype glioblastomas WHO grade IV. MiR-16-5p expression was lower in IDH-mutant than in IDH-wildtype gliomas, and down-regulated in IDH-wildtype glioma lines. MiR-16$5 \mathrm{p}$ overexpression reduced expression of important cell cycle and apoptosis regulators in glioma cells, including CDK6, CDC25A, CCND3, CCNE1, WEE1, CHEK1, BCL2, and MCL1. In line, CDK6, WEE1, CHEK1, BCL2, and MCL1 transcript levels were increased in WHO grade III or IV gliomas. Trichostatin A treatment and HDAC3 knockdown in glioma cells induced miR-16-5p up-regulation and reduced expression of its targets. Moreover, miR-16-5p overexpression inhibited proliferation and induced apoptosis in various glioma cell lines and increased sensitivity of A172 glioma cells to irradiation and temozolomide. CONCLUSION Reduced expression of miR-16-5p contributes to glioma cell proliferation, survival, and resistance to cytotoxic therapy. This article is protected by copyright. All rights reserved.
\end{abstract}

DOI: https://doi.org/10.1111/nan.12532

Posted at the Zurich Open Repository and Archive, University of Zurich

ZORA URL: https://doi.org/10.5167/uzh-161076

Journal Article

Accepted Version

Originally published at:

Krell, Anneliese; Wolter, Marietta; Stojcheva, Nina; Hertler, Caroline; Liesenberg, Franziska; Zapatka, Marc; Weller, Michael; Malzkorn, Bastian; Reifenberger, Guido (2019). MiR-16-5p is frequently downregulated in astrocytic gliomas and modulates glioma cell proliferation, apoptosis, and response to cytotoxic therapy. Neuropathology and Applied Neurobiology, 45(6):441-458.

DOI: https://doi.org/10.1111/nan.12532 


\section{Neuropathology and Applied Neurobiology}

\section{BNS}

MiR-16-5p is frequently down-regulated in astrocytic gliomas and modulates glioma cell proliferation, apoptosis, and response to cytotoxic therapy

\begin{tabular}{|c|c|}
\hline Journal: & Neuropathology and Applied Neurobiology \\
\hline Manuscript ID & NAN-2018-0231.R1 \\
\hline Manuscript Type: & Original Article \\
\hline $\begin{array}{r}\text { Date Submitted by the } \\
\text { Author: }\end{array}$ & 29-Nov-2018 \\
\hline Complete List of Authors: & $\begin{array}{l}\text { Krell, Anneliese; Universitatsklinikum Dusseldorf, Neuropathologie } \\
\text { Wolter, Marietta; Universitatsklinikum Dusseldorf, Neuropathologie } \\
\text { Stojcheva, Nina; UniversitatsSpital Zurich, Neurologie } \\
\text { Hertler, Caroline; UniversitatsSpital Zurich, Neurologie } \\
\text { Liesenberg, Franziska; Universitatsklinikum Dusseldorf, Neuropathologie } \\
\text { Zapatka, Marc; Deutsches Krebsforschungszentrum, Abteilung für } \\
\text { Molekulare Genetik } \\
\text { Weller, Michael; UniversitatsSpital Zurich, Neurologie } \\
\text { Malzkorn, Bastian; Universitatsklinikum Dusseldorf, Neuropathologie } \\
\text { Reifenberger, Guido; Heinrich-Heine-University, ; }\end{array}$ \\
\hline Keywords: & apoptosis, glioma, miR-16-5p, proliferation, temozolomide resistance \\
\hline
\end{tabular}




\section{MiR-16-5p is frequently down-regulated in astrocytic gliomas and modulates glioma cell proliferation, apoptosis, and response to cytotoxic therapy}

Anneliese Krell, ${ }^{1 \#}$ Marietta Wolter, ${ }^{1 \#}$ Nina Stojcheva, ${ }^{2}$ Caroline Hertler, ${ }^{2}$ Franziska Liesenberg, ${ }^{1}$ Marc Zapatka, ${ }^{3}$ Michael Weller, ${ }^{2}$ Bastian Malzkorn, ${ }^{1 *}$ Guido Reifenberger ${ }^{1,4 *}$

1Department of Neuropathology, Heinrich Heine University, Düsseldorf, Germany; ${ }^{2}$ Department of Neurology, University Hospital Zurich, Zurich, Switzerland; ${ }^{3}$ Division of Molecular Genetics, German Cancer Research Center, Heidelberg, Germany; ${ }^{4}$ German Cancer Consortium (DKTK), partner site Essen/Düsseldorf, DKFZ, Heidelberg, Germany

\# These authors share first authorship

* These authors share senior authorship

Corresponding author: Guido Reifenberger, Department of Neuropathology, Heinrich Heine University, Moorenstrasse 5, D-40225 Düsseldorf, Germany, Phone: +49 2118118660 , Fax: +49 2118117804 , Email: reifenberger@uni-duesseldorf.de

Key words: $\quad$ apoptosis, glioma, miR-16-5p, proliferation, temozolomide resistance

Short title: $\quad$ miR-16-5p in astrocytic gliomas

Text word count: 4967 words

Number of figures: 7 (plus 3 Supplementary Figures)

Number of tables: 1 Supplementary Table 


\begin{abstract}
Aims: Aberrant expression of microRNAs (miRNAs) is frequent in various cancers including gliomas. We aimed to characterize the role of $m i R-16-5 p$ as a candidate tumour suppressor miRNA in gliomas.
\end{abstract}

Methods: Real-time PCR-based approaches were used for miRNA and mRNA expression profiling of glioma and non-neoplastic brain tissues as well as glioma cell lines. Protein levels were determined by Western blotting. In vitro analyses were performed following overexpression of miR-16-5p, trichostatin A treatment, and siRNA-mediated knock-down of HDAC3 in glioma cells. Effects of miR-16-5p on glioma cell viability, apoptosis and response to irradiation and temozolomide were assessed.

Results: Expression of miR-16-5p was reduced relative to control brain tissue in isocitrate dehydrogenase (IDH)-mutant astrocytomas of World Health Organization (WHO) grades II, III, and IV, and a subset of IDH-wildtype glioblastomas WHO grade IV. MiR-16-5p expression was lower in IDH-mutant than in IDH-wildtype gliomas, and down-regulated in IDH-wildtype glioma lines. MiR-16-5p overexpression reduced expression of important cell cycle and apoptosis regulators in glioma cells, including CDK6, CDC25A, CCND3, CCNE1, WEE1, CHEK1, BCL2, and MCL1. In line, CDK6, WEE1, CHEK1, BCL2, and MCL1 transcript levels were increased in WHO grade III or IV gliomas. Trichostatin A treatment and HDAC3 knockdown in glioma cells induced miR-16-5p up-regulation and reduced expression of its targets. Moreover, miR-16-5p overexpression inhibited proliferation and induced apoptosis in various glioma cell lines and increased sensitivity of A172 glioma cells to irradiation and temozolomide.

Conclusion: Reduced expression of miR-16-5p contributes to glioma cell proliferation, survival, and resistance to cytotoxic therapy.

\title{
Abstract word count: 248 words
}




\begin{abstract}
Abbreviations used: $\quad \mathrm{CLL}$, chronic lymphocytic leukaemia; IDH, isocitrate dehydrogenase; miRNA, micro-RNA; pre-miR-16-5p, synthetic miR-16-5p precursor molecules; pre-miR-NC, synthetic negative control miRNA precursor molecules; TCGA, The Cancer Genome Atlas; TMZ, temozolomide; TSA, trichostatin A; 3'-UTR, 3'untranslated region; WHO, World Health Organization
\end{abstract}




\section{Introduction}

Gliomas are the most common intrinsic brain tumours and comprise a spectrum of neoplastic lesions with distinct molecular and histological features, biological behaviour, and clinical outcome. The prognosis of glioma patients depends on tumour type and grade according to the World Health Organization (WHO) classification of tumours of the central nervous system (1), as well as on clinical parameters such as patient age, clinical performance status, and extent of tumour resection (2). In addition, molecular biomarkers have been identified that are linked to prognosis and/or response to cytotoxic therapy, such as mutations in the isocitrate dehydrogenase (IDH) genes IDH1 or IDH2, co-deletion of chromosomal arms $1 \mathrm{p}$ and $19 \mathrm{q}$, and $\mathrm{O}^{6}$-methylguanine DNA-methyltransferase (MGMT) promoter methylation (3), with IDH mutation and $1 \mathrm{p} / 19 \mathrm{q}$ codeletion serving as novel diagnostic molecular biomarkers in the WHO classification 2016 (1). IDH-wildtype glioblastoma is the most common and most malignant glioma entity that requires up-front multimodal therapy consisting in surgical resection followed by radiotherapy with concomitant and maintenance temozolomide (TMZ) as the current standard of care $(2,4)$. Despite this aggressive treatment, glioblastomas invariably relapse and become resistant to radio- and chemotherapy. This in turn limits the prognosis to median overall survival times of approximately 16 months in clinical trials and less than 12 months in population-based studies (2). Therefore, it is of paramount importance to better understand the molecular mechanisms driving glioma growth and underlying radio- and chemotherapy resistance in order to develop more effective therapeutic strategies.

Here, we addressed the role of a specific microRNA (miRNA), miR-16-5p, in glioma pathogenesis and therapy resistance. MiRNAs are small, non-coding RNAs that regulate gene expression preferentially by binding to the $3^{\prime}$-untranslated region (3'-UTR) of mRNAs in a sequence specific manner, thereby leading to inhibition of translation and/or enhanced mRNA degradation $(5,6)$. Altered miRNA expression, including down-regulation of tumour 
suppressive and up-regulation of tumour promoting miRNAs, have been identified in many cancers (6), including gliomas (7-9). Among the first miRNAs implicated as tumour suppressors was miR-16-5p, which belongs to a family of evolutionary conserved miRNAs that share a common seed sequence. MiR-16-5p is transcribed from two miRNA clusters on different chromosomes $(10,11)$. The miR-15b-16-2 cluster is located on chromosome 3 intronic to the SMC4 gene, while the miR-15a-16-1 cluster is located on chromosome 13 intronic to the DLEU2 gene $(12,13)$. The latter cluster is frequently affected by deletions in chronic lymphocytic leukaemia (CLL) (14).

Using stem-loop reverse transcription PCR-based expression profiling of 79 astrocytic gliomas, we identified reduced levels of miR-16-5p expression in IDH-mutant astrocytic gliomas and a subset of IDH-wildtype glioblastomas relative to non-neoplastic brain tissue. Subsequent molecular and functional analyses provided further support for a role of miR-16-5p in regulating glioma cell proliferation and apoptosis, as well as modulating response of glioma cells to cytotoxic therapy.

\section{Materials and methods}

\section{Human glioma tissue samples}

Deep-frozen glioma tissue samples were retrieved from the tumour tissue bank at the Department of Neuropathology, Heinrich Heine University, Düsseldorf, Germany, and investigated as approved by the institutional review board (study number 3904). All tumours were classified according to the WHO classification of tumours of the central nervous system (1). Tissue samples used for nucleic acid extraction were histologically evaluated to assure an estimated tumour cell content of $80 \%$ or more. We investigated tumour tissue samples from 79 patients, including seven patients with diffuse astrocytomas, IDH-mutant (WHO grade II), 10 patients with anaplastic astrocytomas, IDH-mutant (WHO grade III), 10 patients 
with glioblastomas, IDH-mutant (WHO grade IV), and 52 patients with glioblastomas, IDHwildtype (WHO grade IV). Ten commercially available RNA samples from non-neoplastic human brain tissues (Ambion, Austin, TX; BioChain, Hayward, CA; Clontech, Mountain View, CA; Stratagene, Cedar Creek, TX) were used as normal tissue reference samples. The IDH mutation status of each tumour was determined by sequencing of the regions encoding IDH1 codon 132 and IDH2 codon $172(15,16)$.

\section{Glioma cell lines}

A172, T98G, U251MG, U138MG, and U87MG cells were purchased from American Type Culture Collection (Manassas, VA, USA). TP365MG cells were provided by Dr. V. P. Collins (Cambridge, UK). Genotyping was performed at the Leibniz Institute DSMZ - German Collection of Microorganisms and Cell Cultures (Braunschweig, Germany) for authentication of each cell line. Glioma cells were grown as monolayer cultures in Dulbecco's modified Eagle's medium (Life Technologies, Darmstadt, Germany) supplemented with $10 \%$ heatinactivated fetal calf serum and $1 \%$ penicillin $\mathrm{G} /$ streptomycin at $37^{\circ} \mathrm{C}$ and $5 \% \mathrm{CO}_{2}$ in a humidified incubator. RNA was extracted from cultured glioma cells using the TRIzol reagent (Life Technologies).

\section{Real-time reverse transcription PCR analyses}

Expression profiling of 79 astrocytic gliomas and 9 non-neoplastic brain samples for differential expression of 365 miRNAs was performed on an ABI PRISM 7900HT system using $\operatorname{TaqMan}^{\circledR}$ Array MicroRNA cards with dye-labelled $\operatorname{TaqMan}^{\circledR}$ probes to monitor amplification (Life Technologies, Foster City, CA). Fluorescent data were converted into cycle threshold measurements by the SDS system software and exported to Microsoft Excel. 
Four miRNAs (miR-30a-5p, miR-30b, miR-30c, miR-30d) with stable expression across the data set were used as reference for data normalization by SLqPCR (17).

Targeted expression analyses of $m i R-16-5 p$ in glioma cell lines were performed on a StepOnePlus ${ }^{\mathrm{TM}}$ Real-Time PCR system (Life Technologies) using the miRCURY LNA ${ }^{\mathrm{TM}}$ Universal RT microRNA PCR kit and LNA ${ }^{T M}$-enhanced PCR primers (Exiqon, Vedbaek, Denmark, miR-16-5p \#205702). Fold expression changes relative to a calibrator sample (Universal Human Reference RNA, Stratagene, Cedar Creek, TX) were calculated with the $2^{-\Delta \Delta C t}$ method (18) using U6 snRNA (Exiqon, \#203907) as reference. Expression of miR-16-5p target genes was determined by real-time reverse transcription-PCR using SYBR Green ${ }^{\circledR}$ (Life Technologies) incorporation and the StepOnePlus ${ }^{\mathrm{TM}}$ system with ARF1 (ADPribosylation factor 1) as reference transcript. Each real-time PCR experiment was performed in technical duplicates. For primer sequences see Supplementary Table 1.

\section{Microarray-based mRNA expression analyses}

Data on mRNA expression analyses of the miR-16-5p targets CDK6, CDC25A, CCND3, CCNE1, WEE1, CHEK1, BCL2, and MCL1 were retrieved from our published microarray data set obtained on 68 gliomas, including eight IDH-mutant diffuse astrocytomas, 10 IDHmutant anaplastic astrocytomas, 11 IDH-mutant glioblastomas, 39 IDH-wildtype glioblastomas, and four non-neoplastic brain tissue samples (16).

\section{Transient transfection of glioma cells}

A172, T98G, and TP365MG glioma cell lines were transiently transfected with 25 or $50 \mathrm{nM}$ precursor-miR-16-5p molecules (pre-miR-16-5p, Ambion ${ }^{\circledR}$, Life Technologies, \#PM10339) for 18 hours using Lipofectamine ${ }^{\mathrm{TM}} 2000$ reagent (Life Technologies). To control for unspecific 
effects of transfection and to monitor transfection efficacy, glioma cells were transiently transfected with scrambled control oligonucleotides, i.e., Cy3-labelled precursor $\mathrm{miR}^{\mathrm{TM}}$ negative control (pre-miR-NC) (Ambion ${ }^{\circledR}$, Life Technologies \#AM17120). Overexpression of miR-16-5p in pre-miR-16-5p-transfected versus pre-miR-NC-transfected cells was determined by real time-reverse transcription PCR.

\section{Western blot analyses}

Glioma cells were transiently transfected with $50 \mathrm{nM}$ of pre-miR-16-5p or pre-miR-NC 24 hours after seeding in 6-well culture plates, followed by protein extraction 72 hours post transfection. Cells were washed twice in ice-cold phosphate-buffered saline (PBS) buffer and lysed in RIPA buffer ( 1 x phosphate-buffered saline (PBS), $1 \%$ Triton X-100, $0.5 \%$ sodium deoxycholate, $0.1 \%$ sodium dodecylsulfate) supplemented with one tablet of Complete Protease Inhibitor Cocktail Tablets and PhosSTOP Phosphatase Inhibitor Cocktail Tablets (Roche, Mannheim, Germany) per $10 \mathrm{ml}$ of RIPA buffer. Cell lysates were centrifuged and protein concentration in the supernatant was determined with the Pierce BCA protein assay kit (Thermo Scientific, Rockford, IL). Twenty-five micrograms of total protein were separated by SDS-PAGE, followed by blotting to PROTRAN $^{\circledR}$ BA83 nitrocellulose membranes (Schleicher \& Schuell BioScience, Dassel, Germany). Membranes were blocked with Odyssey ${ }^{\circledR}$ blocking buffer (LI-COR Biosciences, Lincoln, NE) followed by overnight incubation at $8^{\circ} \mathrm{C}$ with one of the following antibodies diluted in $1 \times$ tris-buffered saline supplemented with $0.1 \%$ Tween-20 (TBS-T): mouse anti-CDK6 (1:500; Cell Signaling, Danvers, MA; \#3136), mouse anti-CCNE1 (1:500, Cell Signaling; \#4129), mouse anti-CHEK1 (1:500, Cell Signaling; \#2360), rabbit anti-BCL2 (1:500, Cell Signaling; \#2870), rabbit anti-MCL1 (1:500, Cell Signaling; \#4572), mouse anti-CDC25A (1:50, Santa Cruz Biotechnology, Dallas, TX; \#sc-7389), mouse anti-WEE1 (1:50, Santa Cruz Biotechnology; \#sc-5285), or mouse antiCCND3 (1:50, Dako, Glosttrup, DK; \#M7156). A rabbit anti-ACTB antibody (1:1000, Abcam, Cambridge, MA; \#ab8227) was used to detect expression of beta-actin as house-keeping 
control. Western blots were washed in 1 x TBS-T followed by incubation with the appropriate secondary antibodies: IRDye 680RD goat anti-mouse IgG (1:10000, LI-COR; \#926-68070), IRDye 800CW goat anti-rabbit IgG (1:10000, LI-COR; \#926-32211), IRDye 800CW goat antimouse IgG (1:10000, LI-COR; \#926-32350), or IRDye 680RD goat anti-rabbit IgG (1:10000, LI-COR; \#926-68071). Protein detection and quantification were performed using the Odyssey ${ }^{\circledR}$ Clx system (LI-COR). Each experiment was performed in triplicate.

\section{Selection of predicted miRNA targets}

Computational target prediction algorithms provided in Pictar (http://pictar.mdc-berlin.de/), and Targetscan 4.0 (http://www.targetscan.org) were used to select candidate targets of miR-16-5p. We specifically focused on targets involved in cell cycle and apoptosis regulation.

\section{3'-UTR luciferase reporter gene assays}

Parts of the $3^{\prime}$-untranslated regions (3'-UTRs) of WEE1, CHEK1, and MCL1 encompassing the predicted miR-16-5p binding sites were amplified by PCR from genomic DNA. Parts of the $3^{\prime}-$ UTR of WEE1 or MCL1 carrying mutated miR-16-5p binding sites were synthesized by Eurofins Genomics (Ebersberg, Germany). Parts of the CHEK1 3'-UTR with mutated binding sites were generated by overlap extension PCR. Wildtype or mutant sequences were cloned between the $\mathrm{Xhol}$ and Notl restriction sites downstream of the Renilla luciferase coding sequence in the psiCHECK ${ }^{\mathrm{TM}}-2$ vector (Promega, Mannheim, Germany). The $\mathrm{psiCHECK}^{\mathrm{TM}}-2$ vector also contains the Firefly luciferase gene whose robust expression from a Herpes simplex virus tyrosine kinase (HSV-TK) promoter allows for normalization of Renilla luciferase expression. Each construct was verified by DNA sequencing. For luciferase reporter gene assays, T98G cells were cultured in 96-well plates and co-transfected with $100 \mathrm{ng}$ of psiCHECK ${ }^{\mathrm{TM}}-2$ vector, either containing the wildtype or the mutated miRNA binding 
sites, and $50 \mathrm{nM}$ of pre-miR-16-5p or pre-miR-NC using Lipofectamine ${ }^{\mathrm{TM}} 2000$ reagent (Life Technologies). Forty-eight or 72 hours after transfection, Firefly and Renilla luciferase activities were measured using the Dual-Glo® Luciferase Assay System (Promega). Experiments consisted of five technical replicates and each transfection was repeated twice. For primer sequences see Supplementary Table 1.

\section{Treatment of glioma cells with trichostatin A}

To screen for histone acetylation-dependent regulation of miR-16-5p expression, A172, T98G, TP365MG, and U138MG glioma cells were incubated 24 hours after seeding in medium containing $1 \mu \mathrm{M}$ trichostatin A (TSA, Merck, Darmstadt, Germany) for 36 hours. Total RNA was then isolated from treated and untreated (control) cells using TRIzol ${ }^{\circledR}$ reagent (Life Technologies), followed by real time RT-PCR analysis for miR-16-5p expression.

\section{SiRNA-mediated knock-down of HDAC3 in glioma cells}

T98G, U87MG or U251MG glioma cells were transiently transfected with $50 \mathrm{nM}$ siRNA against HDAC3 (Qiagen; \#SI00057316 and \#SI00057337) using Lipofectamine ${ }^{\mathrm{TM}} 2000$ reagent (Life Technologies). As control, cells were transiently transfected with Cy3-labelled negative control oligonucleotides (AllStars Negative siRNA Cy3, Qiagen; \#1027281). Knockdown of HDAC3 was verified by real time-reverse transcription PCR and Western blotting. All transfections were performed in three independent experiments. 


\section{Analysis of viability, proliferation and caspase-3/7 activity in glioma cells}

The viability of A172, T98G, and TP365MG glioma cells transfected with pre-miR-16-5p molecules compared to pre-miR-NC-transfected cells was determined 72 hours post transfection using the CellTiter-Gloß Luminescent Cell Viability Assay (Promega, Mannheim, Germany). To analyse the effect of pre-miR-16-5p transfection on proliferation, the BrdUbased cell proliferation chemiluminescent ELISA test (Roche Diagnostics, Mannheim, Germany) was used. Cells were harvested 72 hours post transfection and the BrdU labelling solution was added 12 hours before harvesting. Caspase-3/7 activity in pre-miR-16-5p transfected cells was determined 72 hours post transfection using the luminescence-based Caspase-Glo® 3/7 Assay System (Promega). A Beckman Coulter PARADIGM ${ }^{\mathrm{TM}}$ detection platform was used for measurement of luminescence or fluorescence signals. Each experimental group consisted of five replicates. Each assay was repeated twice.

\section{Determination of cell survival following irradiation or TMZ treatment}

The effect of miR-16-5p on response of glioma cells to irradiation or TMZ was investigated as reported (19). Briefly, T98G or A172 glioma cells were seeded at 300 cells per well in 96-well plates in triplicates, allowed to adhere overnight, and exposed to TMZ at defined concentrations, according to respective EC50 values of each cell line (20), for 24 hours in serum-free medium, followed by an observation period for 2-3 weeks in serum-containing medium until untreated control cells reached confluence. Cell density was assessed by crystal violet staining. TMZ (Schering-Plough, Kenilworth, NJ, USA) was prepared as a stock solution at $100 \mathrm{mM}$ in dimethyl sulfoxide (DMSO, Sigma, St. Louis, MO). For irradiation experiments, cells were irradiated in a 60-Co-radiation source (Gebrüder Sulzer, Thermische Energiesysteme, Winterthur, Switzerland) at defined doses in the range of $1 \mathrm{~Gy}-9 \mathrm{~Gy}$. The fraction of surviving cells following treatment was calculated in \% relative to control cells. 


\section{Association of miR-16-5p expression with molecular markers and overall survival}

Associations of miR-16-5p expression with IDH status and TP53 mutation, as well as overall survival of glioma patients were investigated by using The Cancer Genome Atlas (TCGA) datasets (http://cancergenome.nih.gov/). Expression data were downloaded directly from the GDC data portal (https://portal.gdc.cancer.gov/) and via the cBio Cancer Genomics Portal (www.cbioportal.org) $(21,22)$ using the open-source R package "cgsdr" (version 1.2.5) and the statistical computing language $\mathrm{R}$ (version 3.3.2). Published biomarker information on IDH status and $1 p / 19 q$ codeletion status (23) was used to classify tumours according to the WHO classification (1). To investigate the association of miR-16-5p expression with patient survival, we divided the TCGA cohorts into patients with tumours showing low or high expression using the median level as cut-off. Survival data were obtained from a previous TCGA paper (23). Kaplan-Meier survival probability estimates were calculated using the RPackage "Survival" (version 2.40-1).

\section{Statistical analysis}

Expression differences between glioma groups were analysed by two-sided Student's t-test (two groups) or ANOVA and Dunnett's post-hoc test (multiple groups). Correlation of expression levels was analysed by calculating Pearson's $r$ and a corresponding $p$-value (t-test). Differences in overall survival between patient groups with high and low miRNA expression were investigated by calculating Kaplan-Meier survival curves and use of a logrank-test. Statistical analysis of luminescence (viability, proliferation) or fluorescence (caspase-3/7 activity) values derived from pre-miR-16-5p-transfected versus pre-miR-NCtransfected cells of three independent experiments with five replicates per experimental group were analysed by a mixed model. Two-sided paired Student's t-test was used to compare the mean luminescence values between pre-miR-16-5p- and pre-miR-NCtransfected glioma cells in the luciferase reporter gene assay. TSA-treated glioma cells 
versus control cells and siRNA-transfected versus control-transfected cells were compared using two-sided paired Student's t-test. Cell survival assay results of treated samples were normalized to the respective untreated control values. Significance was assessed using twosided unpaired Student's t-test. Differences or associations were considered as significant with $p<0.05$.

\section{Results}

Reduced expression of miR-16-5p in astrocytic gliomas and glioma cell lines relative to non-neoplastic brain tissue

We performed miRNAs expression profiling of primary tumour samples from 79 patients with astrocytic gliomas of WHO grades II, III or IV using TaqMan® Array microfluid cards. Thereby, we identified reduced mean expression levels of miR-16-5p relative to nonneoplastic brain tissue in IDH-mutant diffuse astrocytomas WHO grade II (Allmut, 5.6-fold reduced mean miR-16-5p expression, $p<0.01)$, IDH-mutant anaplastic astrocytomas of WHO grade III (AAIII ${ }^{\text {mut }}$, 4.9-fold reduced mean miR-16-5p expression, $p<0.01$ ), and IDH-mutant glioblastomas of WHO grade IV (GBIVmut, 3.1-fold reduced mean miR-16-5p expression, $\mathrm{p}<$ 0.05). In IDH-wildtype glioblastomas (GBIVwt), expression of miR-16-5p was more heterogeneous. Although mean expression in this group was not significantly lower as compared to the non-neoplastic brain tissue samples, 34 of 52 investigated tumours showed reduced expression levels relative to the median miR-16-5p expression in the control samples (Fig. 1A). MiR-16-5p expression was significantly lower in 27 IDH-mutant as compared to 52 IDH-wildtype gliomas of our cohort (Fig. 1B). We also investigated six IDHwildtype glioma cell lines (A172, T98G, U251MG, U138MG, U87MG, TP365MG) and found reduced miR-16-5p expression levels relative to non-neoplastic brain tissue samples (Fig. 1C). 


\section{Overexpression of miR-16-5p decreases glioma cell viability, reduces proliferation, and induces caspase-3/7 activity}

To determine the functional roles of $m i R-16-5 p$ in glioma cells, we transiently overexpressed precursor molecules of miR-16-5p (pre-miR-16-5p) or respective non-targeting control oligonucleotides (pre-miR-NC) in three glioma cell lines (A172, T98G, and TP365MG), followed by determination of cell viability (Fig. 2A), proliferation (Fig. 2B) and caspase-3/7 activity (Fig. 2C). Transfection of pre-miR-16-5p significantly decreased cell viability and proliferation in all three cell lines when compared to control-transfected cells. Caspase-3/7 activity was significantly increased by pre-miR-16-5p transfection in the p53-wildtype A172 and TP365MG cell lines but decreased in p53-mutant T98G cells.

\section{Overexpression of miR-16-5p reduces expression of regulators of cell cycle progression and apoptosis in glioma cells}

MicroRNA target prediction showed that miR-16-5p has binding sites in the $3^{\prime}$-UTR of several genes that are involved in cell cycle progression and apoptosis. Most of these miR-16-5p targets have been validated by 3 '-UTR luciferase assays in previous studies, including CDK6, CCND3, and CCNE1 (24, 25), CDC25A (26), WEE1, CHEK1 (27, 28), and $\operatorname{BCL2}(25,29)$. To investigate whether these targets are regulated by miR-16-5p in glioma cells, we transiently transfected A172 glioma cells with pre-miR-16-5p or pre-miR-NC. Overexpression of miR-16-5p resulted in significantly reduced mRNA expression of CDK6, CCND3, CCNE1, CDC25A, WEE1, and CHEK1 in A172 glioma cells (Fig. 3A). Levels of the respective proteins as well as BCL2 and MCL1 also were significantly reduced following miR-16-5p overexpression (Fig. 3B, C). Similar results were obtained in TP365MG and U251MG glioma cells (Suppl. Fig. 1). 


\section{MiR-16-5p directly binds to the 3'-UTRs of WEE1, CHEK1, and MCL1}

To validate that miR-16-5p directly binds to the $3^{\prime}-$ UTR of WEE1, CHEK1, and MCL1, we performed luciferase reporter assays using 3'-UTR fragments of each gene containing either the wildtype or mutated miR-16-5p binding sites. These experiments revealed specific binding of miR-16-5p to the 3'-UTR of all three genes (Fig. 4).

\section{Expression of miR-16-5p target genes in astrocytic gliomas}

To assess mRNA expression of the selected miR-16-5p target genes in glioma tissues, we referred to our published microarray data set (16), which showed that five of the eight investigated miR-16-5p targets (CDK6, WEE1, CHEK1, BCL2, and MCL1) showed significantly higher mRNA expression in anaplastic astrocytomas and/or glioblastomas when compared to non-neoplastic brain tissue (Fig. 5).

\section{Trichostatin A increases miR-16-5p expression in glioma cells}

Involvement of DNA methylation and histone modifications have been implicated in the regulation of miR-16-5p in CLL (30) and non-small cell lung cancer (31). Therefore, we investigated whether treatment of A172, T98G, TP365MG, and U138MG glioma cells with the histone deacetylase inhibitor TSA had an impact on miR-16-5p expression. These experiments revealed significant up-regulation of $m i R-16-5 p$ following TSA treatment in three of the four investigated cell lines (Fig. 6A).

\section{HDAC3 knock-down increases miR-16-5p expression in glioma cells}

Previous studies in non-Hodgkin B-cell lymphomas and non-small cell lung cancers reported that MYC and HDAC3 co-localize to the promoters of the miR-15a/miR-16-1 cluster host gene DLEU2, and that inhibition of HDAC3 increases histone acetylation of these promoters $(31,32)$. To investigate whether a similar mechanism operates in glioma cells, we performed 
knock-down experiments of HDAC3 in the glioma cell lines T98G and U251MG. Knock-down of HDAC3 (Fig. 6B, C) significantly increased expression of miR-16-5p relative to controltransfected cells (Fig. 6D). We additionally investigated the expression of miR-16-5p target genes following HDAC3 knock-down and found that most of the miR-16-5p target genes, including CDK6, CCND3, CCNE1, CDC25A, WEE1, and CHEK1, were significantly downregulated following HDAC3 knock-down (Fig. 6 D, E), Supplementary Figure 3 shows the individual results obtained for expression of $m i R-16-5 p$ and its target genes following HDAC3 knock-down.

\section{Overexpression of miR-16-5p modulates the response of A172 glioma cells to irradiation and chemotherapy}

To assess whether overexpression of $m i R-16-5 p$ modulates the response of glioma cells to irradiation or TMZ, we performed cell survival assays on pre-miR-16-5p- versus pre-miR-NCtransfected A172 and T98G glioma cells using radiation doses ranging from 1 to 9 Gy and $\mathrm{TMZ}$ concentrations ranging from 6.25 to $100 \mu \mathrm{M}$ in $\mathrm{A} 172$ and 150 to $1000 \mu \mathrm{M}$ in T98G cells (Fig. 7). A172 glioma cells are p53-wildtype glioma cells (33) that do not express O6-methylguanine DNA methyltransferase (MGMT) due to hypermethylation of the MGMT promoter (34). In contrast, T98G glioma cells are p53-mutant (33) and express MGMT (35). As reported (34), A172 cells showed higher sensitivity to TMZ treatment than T98G cells (Fig. 7A, B). Sensitivity to $T M Z$ was significantly increased in pre-miR-16-5p-transfected as compared to control-transfected A172 glioma cells (Fig. 7A). Similarly, pre-miR-16-5ptransfected $\mathrm{A} 172$ cells responded better to irradiation at clinically relevant radiation doses (Fig. 7C). In contrast, pre-miR-16-5p transfection did not modulate sensitivity of T98G cells to either TMZ treatment or irradiation (Fig. 7B, D). 


\section{Relationship of miR-16-5p expression with IDH and TP53 mutation status as well as overall survival in the TCGA cohort}

To investigate the relationship of miR-16-5p expression with IDH and TP53 mutation status as well as overall survival of glioblastoma patients, we interrogated TCGA data (http://cancergenome.nih.gov/). MiR-16-5p expression was lower in IDH-mutant than in IDHwildtype gliomas (Supplementary Fig. 2A), thus confirming findings in our institutional cohort (Fig. 1B). As the expression of miR-16-5p may be regulated by p53 $(36,37)$, we also interrogated the TCGA database for a relationship between TP53 mutation and miR-16-5p expression levels but found no association between these parameters (Suppl. Fig. 2B). MiR-16-5p expression was not linked to overall survival in 287 TCGA patients with glioblastomas, IDH-wildtype (WHO grade IV), when stratified according to high versus low expression levels (Suppl. Fig. 2C). Similarly, miR-16-5p expression was not prognostic in 214 TCGA patients with diffuse or anaplastic astrocytomas, IDH-mutant (WHO grades II or III) (Suppl. Fig. 2D).

\section{Discussion}

In this study we report that expression of miR-16-5p is reduced in IDH-mutant astrocytic gliomas as well as a subset of IDH-wildtype glioblastomas relative to non-neoplastic brain tissue. Moreover, miR-16-5p expression is down-regulated in IDH-wildtype glioblastoma cell lines. MiR-16-5p was discovered as a deleted and down-regulated tumour suppressor candidate in B-cell CLL (14). Since then, numerous studies reported on deletion and/or reduced expression of this miRNA in various types of tumours, ranging from pituitary adenoma (38) to carcinomas of the prostate (39), lung (40), pancreas (41), stomach (42), breast (43), and ovaries (44), as well as other cancers (45). Several studies have also addressed expression of miR-16-5p in gliomas, with partly conflicting results. We originally reported that miR-16-5p was up-regulated upon progression of primary low-grade to 
recurrent high-grade gliomas from individual patients (46). However, expression of miR-16-5p was significantly lower in primary and recurrent glioma tissues as compared to non-neoplastic brain tissue, a finding in line with our present data on a larger patient cohort. In contrast, Wuchty et al. (47) reported higher expression levels of miR-16-5p in primary glioblastomas as compared to normal brain tissue. This discrepancy might in part be explained by the use of different reference tissues and our finding that down-regulation of miR-16-5p is more frequent and stronger in IDH-mutant as compared to IDH-wildtype gliomas. Nevertheless, other authors also found increased levels of miR-16-5p, but not of its host gene DLEU2, in glioblastomas and oligodendrogliomas (48). In contrast, studies on glioma cell lines support a tumour suppressive role of $m i R-16-5 p$ by demonstrating inhibitory effects of this miRNA on glioma cell proliferation, migration, invasion and epithelial-tomesenchymal transition, as well as stimulatory effects on apoptosis (49-53). Recent data additionally reported that miR-16-5p inhibits glioma stem cell clonogenicity and xenograft growth (25). In line, we found that $m i R-16-5 p$ inhibited proliferation of three glioma cell lines (A172, TP365MG, T98G) and increased caspase-3/7 activity in two of these (A172, TP365MG). Studies on other cancers including CLL (29), oesophageal carcinoma (54), and non-small cell lung cancer (40), similarly reported on anti-proliferative and pro-apoptotic effects of miR-16-5p, thus establishing its tumour suppressive function.

To investigate mechanisms causing inhibition of glioma growth by miR-16-5p, we investigated eight cell cycle and/or apoptosis regulatory genes that carry binding sites for miR-16-5p, i.e., CDK6, CCND3, CCNE1, CDC25A, WEE1, CHEK1, BCL2, and MCL1. Following transient transfection of miR-16-5p precursor molecules into different glioma cell lines, we found reduced expression of each of these genes at the mRNA and/or protein levels. Previous studies had already shown that miR-16-5p directly binds the $3^{\prime}$-UTR of CDK6, CCND3, CCNE1, CDC25A, and $\operatorname{BCL2}(13,24-26,29,39,40,51,55,56)$. Using $3^{\prime}-$ UTR luciferase reporter assays we confirmed its specific binding to the $3^{\prime}$-UTR of WEE1 and $\operatorname{CHEK1}(27,28)$. Additional $3^{\prime}$-UTR luciferase reporter assays validated MCL1 as a direct miR-16-5p target. Taken together, these data suggest that reduced expression of 
miR-16-5p may promote glioma growth by facilitating up-regulation of positive regulators of cell cycle progression (CDK6, CCND3, CCNE1, CDC25A) and inhibitors of apoptosis (BCL2, MCL1). Moreover, miR-16-5p down-regulation in glioma cells caused increased expression of WEE1 and CHEK1, which may contribute to cell survival by preventing mitotic catastrophe as a consequence of massive replication stress (57-59).

MiR-16-5p overexpression may induce apoptosis by directly down-regulating BCL2 and MCL1 as originally reported in $\operatorname{CLL}(39,60)$. In addition, overexpression of miR-16-5p activated the intrinsic apoptosis pathway via BCL2 in leukaemia cells (29). Former studies implicated BCL2 and MCL1 as important inhibitors of apoptosis also in glioma cells (61-65). Moreover, down-regulation of BCL2 and MCL1 by overexpression of another miRNA, miR153 , has been reported to induce apoptosis of glioma cells (66). Thus, several lines of evidence accumulate to support the hypothesis that reduced expression of miR-16-5p may promote glioma cell survival by preventing apoptosis through facilitating up-regulation of BCL2 and MCL1. At the same time, miR-16-5p down-regulation may facilitate glioma cell proliferation due to enhanced $\mathrm{G} 1 / \mathrm{S}$ phase transition caused by up-regulation of e.g. CDK6 and $\operatorname{CDC} 25 \mathrm{~A}(25,67,68)$.

In line with the in vitro data, we found significantly increased mRNA expression levels of the miR-16-5p target genes CDK6, WEE1, CHECK1, BCL2, and MCL1 in tissue samples of WHO grade III and/or WHO grade IV gliomas relative to non-neoplastic brain tissue, while no clear-cut up-regulation of CCNE1, CDC25A, and CCND3 was detected (16). Moreover, other studies reported on amplification and overexpression of $\operatorname{CDK6}(69,70)$, increased expression of MCL1 and BCL2 (71), as well as up-regulation of WEE1 and CHEK1 expression in malignant gliomas $(58,72)$. Similarly, CDC25A mRNA expression has been reported to increase along with the proliferation rate of gliomas (68).

We also investigated potential mechanisms causing miR-16-5p down-regulation in gliomas. Studies on haematopoietic neoplasms showed that miR-16-5p expression may not only be reduced by copy number losses but also by epigenetic mechanisms, in particular histone 
modifications (30-32). In B-cell lymphoma and lung carcinoma, transcription of DLEU2 and the miR-15a/miR-16-1 locus may be repressed by binding of MYC to DLEU2 promoter regions, followed by recruitment of $\operatorname{HDAC} 3(31,32)$. We provide evidence that a similar mechanism may be active in glioma. We observed that TSA treatment of glioma cells increased miR-16-5p expression, supporting a role of histone modifications in its transcriptional down-regulation. In addition, we showed that siRNA-mediated knock-down of $H D A C 3$ increased the expression of $m i R-16-5 p$ with ensuing down-regulation of $m i R-16-5 p$ target genes.

MiR-16-5p and p53 have been reported to interact in a feedback circuitry loop in CLL, in which p53 transactivates transcription of the miRNA, while the miRNA down-regulates p53 expression $(27,36,60)$. Consequently, CLLs with TP53 alterations showed decreased levels of miR-16-5p as well as elevated MCL1 expression (60). Using TCGA glioma datasets, however, we found no association between TP53 mutation status and miR-16-5p expression, possibly due to the fact that astrocytic gliomas without TP53 mutation typically carry alterations in other p53 pathway genes, such as MDM2 or MDM4 amplification, or p14 ARF homozygous deletion (73).

MiR-16-5p directly regulates the expression of several genes that have been linked to therapy resistance like $B C L 2, M C L 1, W E E 1, C H E K 1$, and $C D K 6(58,61,74-77)$. In gliomas, miR-16 has been reported to modulate TMZ resistance in U251MG glioma cells by regulating BCL2 (78). In addition, miR-195, a member of the $m i R-15 / m i R-16$ family, has been shown to inhibit glioma cell proliferation (79) and to modulate acquired resistance to TMZ (80). Moreover, members of the miR-15/miR-16 family have been linked to resistance against other drugs, including cisplatin, doxorubicin and 5-fluorouracil $(28,81,82)$. Therefore, we addressed potential effects of miR-16-5p overexpression on the response of glioma cells to irradiation and TMZ. We investigated A172 and T98G glioma cells transfected either with miR-16-5p precursors or non-targeting control oligonucleotides for sensitivity to irradiation or $\mathrm{TMZ}$ in vitro. The two cell lines represented a p53-wildtype, MGMT promoter-methylated 
model (A172) and a p53-mutant, MGMT promoter-unmethylated model (T98G). We found that miR-16-5p increased sensitivity to irradiation and TMZ treatment in A172 but not in T98G cells, with the latter cells also being resistant to spontaneous caspase- $3 / 7$ induction upon overexpression of $m i R-16-5 p$. With respect to $m i R-16-5 p$ as a therapeutic target, as it is under investigation in prostate carcinoma and pleural mesothelioma $(83,84)$, our findings suggest that response to miR-16-5p expression in glioma might depend on the genetic background of the tumour cells. This hypothesis, however, would require further experimental evaluation.

In TCGA data sets, we also addressed the question whether miR-16-5p expression is associated with overall survival of glioma patients. Expression of miR-16-5p was associated with overall survival in an institutional cohort of 132 glioblastoma patients (25). However, we found no prognostic role of high versus low miR-16-5p expression in 287 TCGA patients with IDH-wildtype glioblastoma and 214 TCGA patients with IDH-mutant diffuse or anaplastic astrocytomas. This discrepancy may be related to distinct patients cohorts, with the published cohort including younger patients (median age: 45 years) not specified for IDH status (25). In addition, different detection methods and miR-16-5p expression cut-offs were used.

In summary, we report on frequent down-regulation of miR-16-5p expression in astrocytic gliomas relative to non-neoplastic brain tissue, with expression levels being lower in IDH-mutant as compared to IDH-wildtype gliomas. Treatment with TSA or genetic silencing of HDAC3 increased expression of miR-16-5p in glioma cells, suggesting a role of HDAC3mediated histone modification in the transcriptional regulation of $m i R-16-5 p$, as reported for other cancers $(31,32,85)$. Overexpression of $m i R-16-5 p$ in glioma cells reduced expression of CDK6, CDC25A, CCND3, CCNE1, WEE1, CHEK1, BCL2, and MCL1, decreased cell proliferation and increased caspase-3/7 activity. In addition, miR-16-5p overexpression in A172 glioma cells increased sensitivity to irradiation and temozolomide treatment. Thus, miR-16-5p down-regulation may support glioma growth by facilitating higher expression of 
various proteins that promote cell cycle progression and cell survival and may also contribute to resistance to cytotoxic treatment of these tumours. 


\section{References}

1. Louis DN, Perry A, Reifenberger G, Deimling A von, Figarella-Branger D, Cavenee WK et al. The 2016 World Health Organization Classification of Tumours of the Central Nervous System: a summary. Acta Neuropathol 2016; 131(6):803-20.

2. Weller M, van den Bent M, Tonn JC, Stupp R, Preusser M, Cohen-Jonathan-Moyal E et al. European Association for Neuro-Oncology (EANO) guideline on the diagnosis and treatment of adult astrocytic and oligodendroglial gliomas. Lancet Oncol 2017; 18(6):e315-e329.

3. Reifenberger G, Wirsching H-G, Knobbe-Thomsen CB, Weller M. Advances in the molecular genetics of gliomas - implications for classification and therapy. Nat Rev Clin Oncol 2017; 14(7):434-52.

4. Stupp R, Mason WP, van den Bent, Martin J, Weller M, Fisher B, Taphoorn MJB et al. Radiotherapy plus concomitant and adjuvant temozolomide for glioblastoma. N Engl J Med 2005; 352(10):987-96.

5. Hayes J, Peruzzi PP, Lawler S. MicroRNAs in cancer: biomarkers, functions and therapy. Trends Mol Med 2014; 20(8):460-9.

6. Lin S, Gregory RI. MicroRNA biogenesis pathways in cancer. Nat Rev Cancer 2015; 15(6):321-33.

7. Ahir BK, Ozer H, Engelhard HH, Lakka SS. MicroRNAs in glioblastoma pathogenesis and therapy: A comprehensive review. Crit Rev Oncol Hematol 2017; 120:22-33.

8. Ames H, Halushka MK, Rodriguez FJ. miRNA Regulation in Gliomas: Usual Suspects in Glial Tumorigenesis and Evolving Clinical Applications. J Neuropathol Exp Neurol 2017; 76(4):246-54.

9. Banelli B, Forlani A, Allemanni G, Morabito A, Pistillo MP, Romani M. MicroRNA in Glioblastoma: An Overview. Int J Genomics 2017; 2017:7639084.

10. Finnerty JR, Wang W-X, Hébert SS, Wilfred BR, Mao G, Nelson PT. The miR-15/107 group of microRNA genes: evolutionary biology, cellular functions, and roles in human diseases. J Mol Biol 2010; 402(3):491-509.

11. Yue J, Tigyi G. Conservation of miR-15a/16-1 and miR-15b/16-2 clusters. Mamm Genome 2010; 21(1-2):88-94.

12. Garding A, Bhattacharya N, Claus R, Ruppel M, Tschuch C, Filarsky K et al. Epigenetic upregulation of IncRNAs at $13 q 14.3$ in leukaemia is linked to the In Cis downregulation of a gene cluster that targets NF-kB. PLoS Genet 2013; 9(4):e1003373. 
13. Lerner M, Harada M, Lovén J, Castro J, Davis Z, Oscier D et al. DLEU2, frequently deleted in malignancy, functions as a critical host gene of the cell cycle inhibitory microRNAs miR-15a and miR-16-1. Exp Cell Res 2009; 315(17):2941-52.

14. Calin GA, Dumitru CD, Shimizu M, Bichi R, Zupo S, Noch E et al. Frequent deletions and down-regulation of micro- RNA genes miR15 and miR16 at 13q14 in chronic lymphocytic leukaemia. Proc Natl Acad Sci U S A 2002; 99(24):15524-9.

15. Felsberg J, Wolter M, Seul H, Friedensdorf B, Göppert M, Sabel MC et al. Rapid and sensitive assessment of the IDH1 and IDH2 mutation status in cerebral gliomas based on DNA pyrosequencing. Acta Neuropathol 2010; 119(4):501-7.

16. Toedt G, Barbus S, Wolter M, Felsberg J, Tews B, Blond F et al. Molecular signatures classify astrocytic gliomas by IDH1 mutation status. Int J Cancer 2011; 128(5):1095-103.

17. Vandesompele J, Preter K de, Pattyn F, Poppe B, van Roy N, Paepe A de et al. Accurate normalization of real-time quantitative RT-PCR data by geometric averaging of multiple internal control genes. Genome Biol 2002; 3(7):RESEARCH0034.

18. Livak KJ, Schmittgen TD. Analysis of relative gene expression data using real-time quantitative PCR and the 2(-Delta Delta C(T)) Method. Methods 2001; 25(4):402-8.

19. Happold C, Roth P, Silginer M, Florea A-M, Lamszus K, Frei K et al. Interferon- $\beta$ induces loss of spherogenicity and overcomes therapy resistance of glioblastoma stem cells. Mol Cancer Ther 2014; 13(4):948-61.

20. Hermisson M, Klumpp A, Wick W, Wischhusen J, Nagel G, Roos W et al. O6methylguanine DNA methyltransferase and p53 status predict temozolomide sensitivity in human malignant glioma cells. J Neurochem 2006; 96(3):766-76.

21. Cerami E, Gao J, Dogrusoz U, Gross BE, Sumer SO, Aksoy BA et al. The cBio cancer genomics portal: an open platform for exploring multidimensional cancer genomics data. Cancer Discov 2012; 2(5):401-4.

22. Gao J, Ciriello G, Sander C, Schultz N. Collection, integration and analysis of cancer genomic profiles: from data to insight. Curr Opin Genet Dev 2014; 24:92-8.

23. Ceccarelli M, Barthel FP, Malta TM, Sabedot TS, Salama SR, Murray BA et al. Molecular Profiling Reveals Biologically Discrete Subsets and Pathways of Progression in Diffuse Glioma. Cell 2016; 164(3):550-63.

24. Liu Q, Fu H, Sun F, Zhang H, Tie $Y$, Zhu J et al. miR-16 family induces cell cycle arrest by regulating multiple cell cycle genes. Nucleic Acids Res 2008; 36(16):5391-404. 
25. Tian R, Wang J, Yan H, Wu J, Xu Q, Zhan X et al. Differential expression of miR16 in glioblastoma and glioblastoma stem cells: their correlation with proliferation, differentiation, metastasis and prognosis. Oncogene 2017; 36(42):5861-73.

26. Pothof J, Verkaik NS, van IJcken W, Wiemer EAC, van Ta TB, van der Horst, Gijsbertus $\mathrm{T} \mathrm{J}$ et al. MicroRNA-mediated gene silencing modulates the UV-induced DNA-damage response. EMBO J 2009; 28(14):2090-9.

27. Lezina L, Purmessur N, Antonov AV, Ivanova T, Karpova E, Krishan K et al. miR-16 and miR-26a target checkpoint kinases Wee1 and Chk1 in response to p53 activation by genotoxic stress. Cell Death Dis 2013; 4:e953.

28. Pouliot LM, Chen Y-C, Bai J, Guha R, Martin SE, Gottesman MM et al. Cisplatin sensitivity mediated by WEE 1 and CHK1 is mediated by miR-155 and the miR-15 family. Cancer Res 2012; 72(22):5945-55.

29. Cimmino A, Calin GA, Fabbri M, lorio MV, Ferracin M, Shimizu M et al. miR-15 and miR16 induce apoptosis by targeting BCL2. Proc Natl Acad Sci U S A 2005; 102(39):13944-9.

30. Sampath D, Liu C, Vasan K, Sulda M, Puduvalli VK, Wierda WG et al. Histone deacetylases mediate the silencing of miR-15a, miR-16, and miR-29b in chronic lymphocytic leukaemia. Blood 2012; 119(5):1162-72.

31. Chen C-Q, Chen C-S, Chen J-J, Zhou L-P, Xu H-L, Jin W-W et al. Histone deacetylases inhibitor trichostatin A increases the expression of Dleu2/miR-15a/16-1 via HDAC3 in nonsmall cell lung cancer. Mol Cell Biochem 2013; 383(1-2):137-48.

32. Zhang X, Chen X, Lin J, Lwin T, Wright G, Moscinski LC et al. Myc represses miR15a/miR-16-1 expression through recruitment of HDAC3 in mantle cell and other nonHodgkin B-cell lymphomas. Oncogene 2012; 31(24):3002-8.

33. Ishii N, Maier D, Merlo A, Tada M, Sawamura Y, Diserens AC et al. Frequent coalterations of TP53, p16/CDKN2A, p14ARF, PTEN tumour suppressor genes in human glioma cell lines. Brain Pathol 1999; 9(3):469-79.

34. Gaspar N, Marshall L, Perryman L, Bax DA, Little SE, Viana-Pereira M et al. MGMTindependent temozolomide resistance in pediatric glioblastoma cells associated with a PI3kinase-mediated HOX/stem cell gene signature. Cancer Res 2010; 70(22):9243-52.

35. Wang X, Chen J-x, Liu Y-h, You C, Mao Q. Mutant TP53 enhances the resistance of glioblastoma cells to temozolomide by up-regulating $O(6)$-methylguanine DNAmethyltransferase. Neurol Sci 2013; 34(8):1421-8. 
36. Fabbri M, Bottoni A, Shimizu M, Spizzo R, Nicoloso MS, Rossi S et al. Association of a microRNA/TP53 feedback circuitry with pathogenesis and outcome of B-cell chronic lymphocytic leukaemia. JAMA 2011; 305(1):59-67.

37. Shi L, Jackstadt R, Siemens H, Li H, Kirchner T, Hermeking H. p53-induced miR-15a/161 and AP4 form a double-negative feedback loop to regulate epithelial-mesenchymal transition and metastasis in colorectal cancer. Cancer Res 2014; 74(2):532-42.

38. Bottoni A, Piccin D, Tagliati F, Luchin A, Zatelli MC, Degli Uberti EC. miR-15a and miR16-1 down-regulation in pituitary adenomas. J Cell Physiol 2005; 204(1):280-5.

39. Bonci D, Coppola V, Musumeci M, Addario A, Giuffrida R, Memeo L et al. The miR-15amiR-16-1 cluster controls prostate cancer by targeting multiple oncogenic activities. Nat Med 2008; 14(11):1271-7.

40. Bandi N, Zbinden S, Gugger M, Arnold M, Kocher V, Hasan L et al. miR-15a and miR-16 are implicated in cell cycle regulation in a $\mathrm{Rb}$-dependent manner and are frequently deleted or down-regulated in non-small cell lung cancer. Cancer Res 2009; 69(13):5553-9.

41. Jiao LR, Frampton AE, Jacob J, Pellegrino L, Krell J, Giamas G et al. MicroRNAs targeting oncogenes are down-regulated in pancreatic malignant transformation from benign tumours. PLoS ONE 2012; 7(2):e32068.

42. Kang W, Tong JHM, Lung RWM, Dong Y, Zhao J, Liang Q et al. Targeting of YAP1 by microRNA-15a and microRNA-16-1 exerts tumour suppressor function in gastric adenocarcinoma. Mol Cancer 2015; 14:52.

43. Rivas MA, Venturutti L, Huang Y-W, Schillaci R, Huang TH-M, Elizalde PV. Downregulation of the tumour-suppressor miR-16 via progestin-mediated oncogenic signaling contributes to breast cancer development. Breast Cancer Res 2012; 14(3):R77.

44. Bhattacharya R, Nicoloso M, Arvizo R, Wang E, Cortez A, Rossi S et al. MiR-15a and MiR-16 control Bmi-1 expression in ovarian cancer. Cancer Res 2009; 69(23):9090-5.

45. Aqeilan RI, Calin GA, Croce CM. miR-15a and miR-16-1 in cancer: discovery, function and future perspectives. Cell Death Differ 2010; 17(2):215-20.

46. Malzkorn B, Wolter M, Liesenberg F, Grzendowski M, Stühler K, Meyer HE et al. Identification and functional characterization of microRNAs involved in the malignant progression of gliomas. Brain Pathol 2010; 20(3):539-50.

47. Wuchty S, Arjona D, Li A, Kotliarov Y, Walling J, Ahn S et al. Prediction of Associations between microRNAs and Gene Expression in Glioma Biology. PLoS ONE 2011; 6(2):e14681. 
48. Lages E, Guttin A, El Atifi M, Ramus C, Ipas H, Dupré I et al. MicroRNA and target protein patterns reveal physiopathological features of glioma subtypes. PLoS ONE 2011; 6(5):e20600.

49. Li X, Ling N, Bai Y, Dong W, Hui G-Z, Liu D et al. MiR-16-1 plays a role in reducing migration and invasion of glioma cells. Anat Rec (Hoboken) 2013; 296(3):427-32.

50. Wang Q, Li X, Zhu Y, Yang P. MicroRNA-16 suppresses epithelial-mesenchymal transition-related gene expression in human glioma. Mol Med Rep 2014; 10(6):3310-4.

51. Yang T-Q, Lu X-J, Wu T-F, Ding D-D, Zhao Z-H, Chen G-L et al. MicroRNA-16 inhibits glioma cell growth and invasion through suppression of BCL2 and the nuclear factorKB1/MMP9 signaling pathway. Cancer Sci 2014; 105(3):265-71.

52. Zhan X-H, Xu Q-Y, Tian R, Yan H, Zhang M, Wu J et al. MicroRNA16 regulates glioma cell proliferation, apoptosis and invasion by targeting Wip1-ATM-p53 feedback loop. Oncotarget 2017; 8(33):54788-98.

53. Zhou Y, Liu Y, Hu C, Jiang Y. MicroRNA-16 inhibits the proliferation, migration and invasion of glioma cells by targeting Sal-like protein 4. Int J Mol Med 2016; 38(6):1768-76.

54. Zhu Y, Xia Y, Niu H, Chen Y. MiR-16 induced the suppression of cell apoptosis while promote proliferation in oesophageal squamous cell carcinoma. Cell Physiol Biochem 2014; 33(5):1340-8.

55. Wang $F, F u ~ X-D$, Zhou $Y$, Zhang $Y$. Down-regulation of the cyclin E1 oncogene expression by microRNA-16-1 induces cell cycle arrest in human cancer cells. BMB Rep 2009; 42(11):725-30.

56. Yu X, Zhang X, Dhakal IB, Beggs M, Kadlubar S, Luo D. Induction of cell proliferation and survival genes by estradiol-repressed microRNAs in breast cancer cells. BMC Cancer 2012; $12: 29$.

57. Cornago M, Garcia-Alberich C, Blasco-Angulo N, Vall-Llaura N, Nager M, Herreros J et al. Histone deacetylase inhibitors promote glioma cell death by $\mathrm{G} 2$ checkpoint abrogation leading to mitotic catastrophe. Cell Death Dis 2014; 5:e1435.

58. Mir SE, De Witt Hamer, Philip C, Krawczyk PM, Balaj L, Claes A, Niers JM et al. In silico analysis of kinase expression identifies WEE1 as a gatekeeper against mitotic catastrophe in glioblastoma. Cancer Cell 2010; 18(3):244-57.

59. Sørensen CS, Syljuåsen RG. Safeguarding genome integrity: the checkpoint kinases ATR, CHK1 and WEE1 restrain CDK activity during normal DNA replication. Nucleic Acids Res 2012; 40(2):477-86. 
60. Liu J, Chen G, Feng L, Zhang W, Pelicano H, Wang F et al. Loss of p53 and altered miR15-a/16-1 $\square$ MCL-1 pathway in CLL: insights from TCL1-Tg:p53(-/-) mouse model and primary human leukaemia cells. Leukemia 2014; 28(1):118-28.

61. Gratas C, Séry Q, Rabé M, Oliver L, Vallette FM. Bak and Mcl-1 are essential for Temozolomide induced cell death in human glioma. Oncotarget 2014; 5(9):2428-35.

62. Murphy ÁC, Weyhenmeyer B, Noonan J, Kilbride SM, Schimansky S, Loh KP et al. Modulation of $\mathrm{Mcl}-1$ sensitizes glioblastoma to TRAIL-induced apoptosis. Apoptosis 2014; 19(4):629-42.

63. Roth W, Grimmel C, Rieger L, Strik H, Takayama S, Krajewski S et al. Bag-1 and Bcl-2 gene transfer in malignant glioma: modulation of cell cycle regulation and apoptosis. Brain Pathol 2000; 10(2):223-34.

64. Strik H, Deininger M, Streffer J, Grote E, Wickboldt J, Dichgans J et al. BCL-2 family protein expression in initial and recurrent glioblastomas: modulation by radiochemotherapy. $\mathrm{J}$ Neurol Neurosurg Psychiatry 1999; 67(6):763-8.

65. Weller M, Malipiero U, Aguzzi A, Reed JC, Fontana A. Protooncogene bcl-2 gene transfer abrogates Fas/APO-1 antibody-mediated apoptosis of human malignant glioma cells and confers resistance to chemotherapeutic drugs and therapeutic irradiation. $\mathrm{J}$ Clin Invest 1995; 95(6):2633-43.

66. Xu J, Liao X, Wong C. Downregulations of B-cell lymphoma 2 and myeloid cell leukaemia sequence 1 by microRNA 153 induce apoptosis in a glioblastoma cell line DBTRG-05MG. Int J Cancer 2010; 126(4):1029-35.

67. Bellail AC, Olson JJ, Hao C. SUMO1 modification stabilizes CDK6 protein and drives the cell cycle and glioblastoma progression. Nat Commun 2014; 5:4234.

68. Yamashita Y, Kasugai I, Sato M, Tanuma N, Sato I, Nomura M et al. CDC25A mRNA levels significantly correlate with $\mathrm{Ki}-67$ expression in human glioma samples. J Neurooncol 2010; 100(1):43-9.

69. Costello JF, Plass C, Arap W, Chapman VM, Held WA, Berger MS et al. Cyclindependent kinase 6 (CDK6) amplification in human gliomas identified using two-dimensional separation of genomic DNA. Cancer Res 1997; 57(7):1250-4.

70. Lam PY, Di Tomaso E, Ng HK, Pang JC, Roussel MF, Hjelm NM. Expression of p19INK4d, CDK4, CDK6 in glioblastoma multiforme. Br J Neurosurg 2000; 14(1):28-32.

71. Krajewski S, Krajewska M, Ehrmann J, Sikorska M, Lach B, Chatten J et al. Immunohistochemical analysis of $\mathrm{Bcl}-2, \mathrm{Bcl}-\mathrm{X}, \mathrm{Mcl}-1$, and $\mathrm{Bax}$ in tumours of central and peripheral nervous system origin. Am J Pathol 1997; 150(3):805-14. 
72. Seol HJ, Yoo HY, Jin J, Joo KM, Kong D-S, Yoon SJ et al. Prognostic implications of the DNA damage response pathway in glioblastoma. Oncol Rep 2011; 26(2):423-30.

73. The Cancer Genome Atlas Research Network. Comprehensive genomic characterization defines human glioblastoma genes and core pathways. Nature 2008; 455(7216):1061-8.

74. Hirose Y, Berger MS, Pieper RO. Abrogation of the Chk1-mediated G(2) checkpoint pathway potentiates temozolomide-induced toxicity in a p53-independent manner in human glioblastoma cells. Cancer Res 2001; 61(15):5843-9.

75. Kwon J-E, Kim B-Y, Kwak S-Y, Bae I-H, Han Y-H. lonizing radiation-inducible microRNA miR-193a-3p induces apoptosis by directly targeting Mcl-1. Apoptosis 2013; 18(7):896-909.

76. Li B, He H, Tao B-B, Zhao Z-Y, Hu G-H, Luo C et al. Knockdown of CDK6 enhances glioma sensitivity to chemotherapy. Oncol Rep 2012; 28(3):909-14.

77. Li R-Y, Chen L-C, Zhang H-Y, Du W-Z, Feng Y, Wang H-B et al. MiR-139 inhibits Mcl-1 expression and potentiates TMZ-induced apoptosis in glioma. CNS Neurosci Ther 2013; 19(7):477-83.

78. Han J, Chen Q. MiR-16 modulate temozolomide resistance by regulating BCL-2 in human glioma cells. Int J Clin Exp Pathol 2015; 8(10):12698-707.

79. Hui W, Yuntao L, Lun L, WenSheng L, ChaoFeng L, HaiYong H et al. MicroRNA-195 inhibits the proliferation of human glioma cells by directly targeting cyclin D1 and cyclin E1. PLoS ONE 2013; 8(1):e54932.

80. Ujifuku K, Mitsutake N, Takakura S, Matsuse M, Saenko V, Suzuki K et al. miR-195, miR455-3p and miR-10a $\left(^{*}\right)$ are implicated in acquired temozolomide resistance in glioblastoma multiforme cells. Cancer Lett 2010; 296(2):241-8.

81. Patel N, Garikapati KR, Pandita RK, Singh DK, Pandita TK, Bhadra U et al. miR15a/miR-16 down-regulates BMI1, impacting Ub-H2A mediated DNA repair and breast cancer cell sensitivity to doxorubicin. Sci Rep 2017; 7(1):4263.

82. Xia L, Zhang D, Du R, Pan Y, Zhao L, Sun $S$ et al. miR-15b and miR-16 modulate multidrug resistance by targeting BCL2 in human gastric cancer cells. Int J Cancer 2008; 123(2):372-9.

83. Takeshita F, Patrawala L, Osaki M, Takahashi R-u, Yamamoto Y, Kosaka N et al. Systemic delivery of synthetic microRNA-16 inhibits the growth of metastatic prostate tumours via downregulation of multiple cell-cycle genes. Mol Ther 2010; 18(1):181-7.

84. van Zandwijk N, Pavlakis N, Kao SC, Linton A, Boyer MJ, Clarke S et al. Safety and activity of microRNA-loaded minicells in patients with recurrent malignant pleural 
mesothelioma: a first-in-man, phase 1, open-label, dose-escalation study. Lancet Oncol 2017; 18(10):1386-96.

85. Kawano M, Tanaka K, Itonaga I, Iwasaki T, Tsumura H. c-Myc Represses TumorSuppressive microRNAs, let-7a, miR-16 and miR-29b, and Induces Cyclin D2-Mediated Cell Proliferation in Ewing's Sarcoma Cell Line. PLoS ONE 2015; 10(9):e0138560.

\section{Acknowledgements}

This study was supported by a grant from the Wilhelm Sander Foundation to MiWe, $\mathrm{CH}$ and GR (grant no. 2012.088.1) and a start-up grant from the Research Commission of the Medical Faculty of Heinrich Heine University to B.M. (grant no. 45/2010). We thank Professor V. Peter Collins, Cambridge, UK, for kindly providing the TP365MG glioma cell line. Parts of the reported results are based on data generated by the TCGA Research Network (http://cancergenome.nih.gov/).

\section{Author Contributions}

AK, MaWo, BM and GR designed the study protocol. AK and FL performed experiments based on primary glioma tissue samples and glioma cell cultures, and evaluated the data with the help of MaWo, BM and GR. MZ performed the biostatistical evaluations of the miRNA expression data. NS, $\mathrm{CH}$ and MiWe investigated the effect of irradiation and temozolomide on glioma cell lines following miR-16-5p overexpression. BM performed the TCGA data analyses. AK, MaWo, BM, CH and GR designed the figures. AK and GR wrote the manuscript with contributions and final approval by all authors.

\section{Conflicts of interest}

MiWe has received research grants from Abbvie, Acceleron, Actelion, Bayer, Merck, Sharp \& Dohme (MSD), Merck (EMD), Novocure, OGD2, Piqur, Roche and Tragara, and honoraria for lectures or advisory board participation or consulting from Abbvie, BMS, Celgene, Celldex, Merck, Sharp \& Dohme (MSD), Merck (EMD), Novocure, Orbus, Pfizer, Progenics, Roche, Teva and Tocagen. GR has received research grants from Roche and Merck, and 
honoraria for advisory boards from Abbvie. The other authors declare no conflict of interest. The Editors of Neuropathology and Applied Neurobiology are committed to peer review integrity and upholding the highest standards of review. As such, this article was peer reviewed by independent, anonymous expert referees and the corresponding author (GR) had no role in either the editorial decision or the handling of the paper.

\section{Supplementary material}

Supplementary material is available online at the journal's homepage. 


\section{Legends to the figures}

Figure 1. Expression of miR-16-5p in gliomas and glioma cell lines. (A, B) MiR-16-5p expression profiling using TaqMan® Array MicroRNA Cards in 9 non-neoplastic brain tissue (NB) and 79 gliomas including 7 diffuse astrocytomas, IDH-mutant, WHO grade II (Allmut), 10 anaplastic astrocytomas, IDH-mutant, WHO grade III (AAIIImut), 10 glioblastomas, IDHmutant, WHO grade IV (GBIVmut), and 52 glioblastomas, IDH-wildtype, WHO grade IV (GBIVwt). Box plots indicate normalized median expression values as well as lower and upper quartiles. Whiskers indicate lowest and highest expression levels. (A) Glioma groups were compared to the NB group by ANOVA and Dunnett's post hoc test. (B) 52 IDH-wildtype were compared to 27 IDH-mutant gliomas using two-sided unpaired Student's t-test (C) MiR-16-5p expression as determined by targeted realtime RT-PCR. Six glioma cell lines (A172, T98G, TP365MG, U138MG, U87MG, U251MG, abbreviated as CL) were compared to ten nonneoplastic brain tissue samples (NB) using two-sided unpaired Student's t-test. In all graphs, asterisks indicate significant expression differences $\left({ }^{*}, p<0.05 ;{ }^{* *}, p<0.01\right.$; $* * * *, p<0.0001)$.

Figure 2. Decreased viability and proliferation as well as increased caspase-3/7 activity following overexpression of miR-16-5p in glioma cells. Glioma cells were transiently transfected with $25 \mathrm{nM}$ (viability and proliferation) or $50 \mathrm{nM}$ (caspase-3/7 activity) pre-miR-16-5p or pre-miR-NC controls for 72 hours. Graphs depict cell viability (A), proliferation (B) and caspase-3/7 activity (C) for the cell lines A172, TP98G, and TP365MG. Dots represent the mean of 5 replicate measurements. Three independent experiments were performed per cell line. P-values are calculated using a mixed model. For calculations, the fixed variable was the transfection group and the random variable was the week of transfection. RLU, relative luminescence units; RFU, relative fluorescence units. 
Figure 3. MRNA expression and protein levels of selected miR-16-5p target genes following transfection of miR-16-5p precursors in A172 glioma cells. (A) Shown are results of realtime-RT-PCR expression analyses using ARF1 as reference transcript. Three independent experiments were performed. P-values refer to two-sided paired Student's ttests. Note reduced expression of CDK6, CCND3, CCNE1, CDC25A, WEE1, and CHEK1 but not BCL2 and MCL1 transcripts after miR-16-5p overexpression. Exemplary results of Western blot analyses (B) and its quantifications (C) in A172 glioma cells transiently transfected with pre-miR-16-5p or pre-miR-NC are shown. Blots were immunostained for $ß-$ actin (ACTB) to normalize the protein levels in the individual lanes. Note that all eight target proteins, including BCL2 and MCL1, were down-regulated by miR-16-5p overexpression relative to control transfected cells $(\mathbf{B}, \mathbf{C})$.

Figure 4. Demonstration of direct binding of miR-16-5p to the 3'-UTRs of WEE1, CHEK1, and MCL1 using luciferase reporter assay. (A) Schematic representation of miR-16-5p binding sites in the $3^{\prime}-\mathrm{UTR}$ of the target genes WEE1, CHEK1, MCL1 that were cloned into psiCHECK-2 ${ }^{\mathrm{TM}}$ plasmids with flanking nucleotides. Bold bases represent bases comprising the recognition sites for the miRNA seed sequence that were mutated (mut, mut1, mut2, mut1,2) to ensure specific miRNA binding. (B) T98G glioma cells were transiently co-transfected with either $100 \mathrm{ng}$ WEE1, CHEK1 or MCL1 wildtype (wt) or mutated $3^{\prime}-U_{T R}$ reporter constructs and $50 \mathrm{nM}$ pre-miR-16-5p or pre-miR-NC for 72 hours (WEE1) or 48 hours (CHEK1 and MCL1). Bars and error bars represent the mean results of three independent experiments and standard errors of the mean. Each experiment comprised 5 replicates. P-values refer to two-sided, paired Student's t-tests $\left({ }^{*}, p<0.05\right.$; $\left.{ }^{* * *}, p<0.001\right) . R L U$, relative luminescence units.

Figure 5. MRNA expression of several miR-16-5p target genes in gliomas. Results of microarray expression analyses of four non-neoplastic brain tissue (NB) and 68 human gliomas, including 8 Allmut, 10 AAll mut, 11 GBIVmut, and 39 GBIVwt are shown. Box plots are 
depicted indicating median expression as well as lower and upper quartiles. Whiskers indicate lowest and highest expression values. Comparison between each tumour group and the non-neoplastic brain tissue group (NB) was performed by ANOVA and Dunnett's post hoc test. Asterisks indicate significant expression differences $\left({ }^{*}, p<0.05 ;{ }^{* *}, p<0.01\right.$; $\left.{ }^{* * *}, p<0.001\right)$.

Figure 6. Treatment with trichostatin $A$ (TSA) as well as siRNA-mediated HDAC3 knockdown increases miR-16-5p expression in glioma cells. (A) Glioma cells were treated with $1 \mu \mathrm{M}$ TSA for 36 hours. Shown are real-time RT-PCR results for miR-16-5p in A172, T98G, TP365MG, and U138MG cells. Each dot represents data from two technical replicates. Three independent experiments were performed. (B-D) Results of HDAC3 knockdown in T98G and U251MG glioma cells. Transfection of two siRNAs against HDAC3 (si_HDAC3-1, si_HDAC3-2) effectively reduced HDAC3 at the mRNA (B) and protein level (C) as compared to control transfected cells (si_NC). ARF1 was used to normalize mRNA expression and ACTB to normalize protein expression. HDAC3 knockdown resulted in significantly increased expression (black squares) of miR-16-5p as well as significantly reduced expression (white squares) of most of the investigated miR-16-5p target genes. Three independent transfections were performed. P-values were calculated using the twosided, paired Student's t-test $\left({ }^{*}, p<0.05 ;{ }^{* *} p<0.01\right)$.

Figure 7. Modulation of glioma cell sensitivity to irradiation and temozolomide treatment by transfection of miR-16-5p precursors. Pre-miR-16-5p-transfected (black squares) or pre-miR-NC control-transfected (open circles) A172 cells (A, C) or T98G cells (B, D) were exposed to increasing concentrations of $T M Z$ for $24 \mathrm{~h}(\mathrm{~A}, \mathrm{~B})$ or irradiated at increasing doses (C, D) and allowed to grow for 2-3 weeks in complete medium. Cell density was assessed by crystal violet staining. Data were assessed in triplets. Shown are diagrams of one of three independent replica experiments each $\left({ }^{*}, p<0.05 ;{ }^{* *}, p<0.01 ;{ }^{* * *}, p<0.001\right.$, two-sided student's T-test). 
A

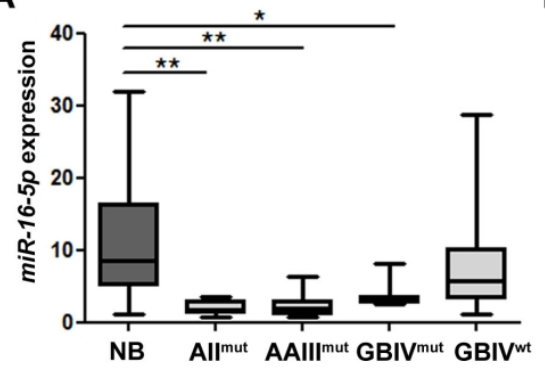

B

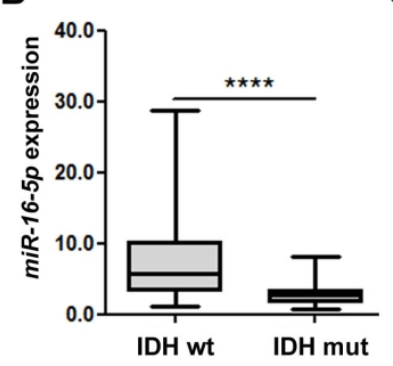

C

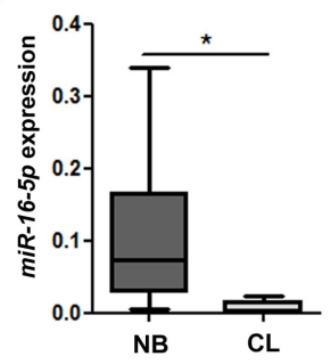

Figure 1. Expression of miR-16-5p in gliomas and glioma cell lines. (A, B) MiR-16-5p expression profiling using TaqMan ${ }^{\circ}$ Array MicroRNA Cards in 9 non-neoplastic brain tissue (NB) and 79 gliomas including 7 diffuse astrocytomas, IDH-mutant, WHO grade II (AIImut), 10 anaplastic astrocytomas, IDH-mutant, WHO grade III (AAIIImut), 10 glioblastomas, IDH-mutant, WHO grade IV (GBIVmut), and 52 glioblastomas, IDHwildtype, WHO grade IV (GBIVwt). Box plots indicate normalized median expression values as well as lower and upper quartiles. Whiskers indicate lowest and highest expression levels. (A) Glioma groups were compared to the NB group by ANOVA and Dunnett's post hoc test. (B) $52 \mathrm{IDH}$-wildtype were compared to 27 IDH-mutant gliomas using two-sided unpaired Student's t-test (C) MiR-16-5p expression as determined by targeted realtime RT-PCR. Six glioma cell lines (A172, T98G, TP365MG, U138MG, U87MG, U251MG, abbreviated as $\mathrm{CL}$ ) were compared to ten non-neoplastic brain tissue samples (NB) using two-sided unpaired Student's t-test. In all graphs, asterisks indicate significant expression differences $(*, p<0.05 ; * *, p<$ $0.01 ; * * * *, \mathrm{p}<0.0001)$. 
TP365MG
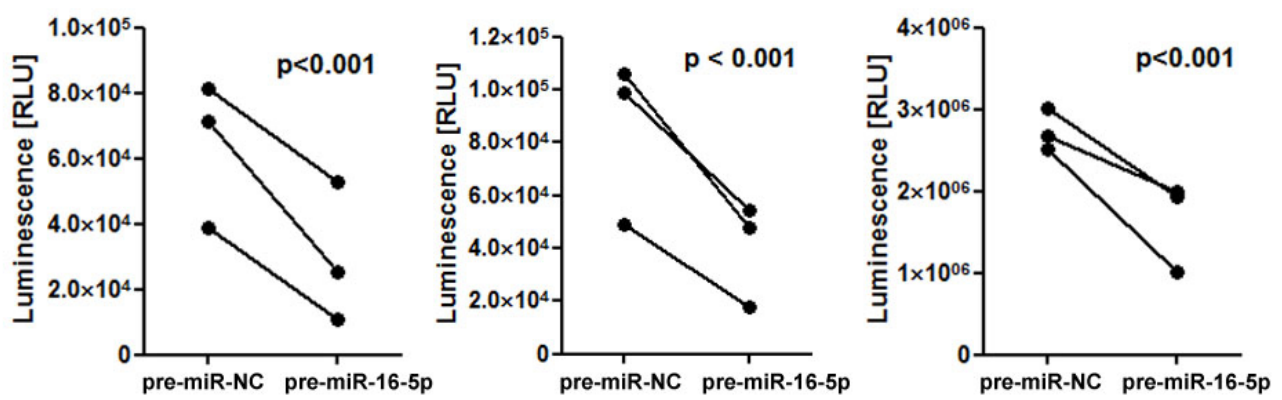

$B$
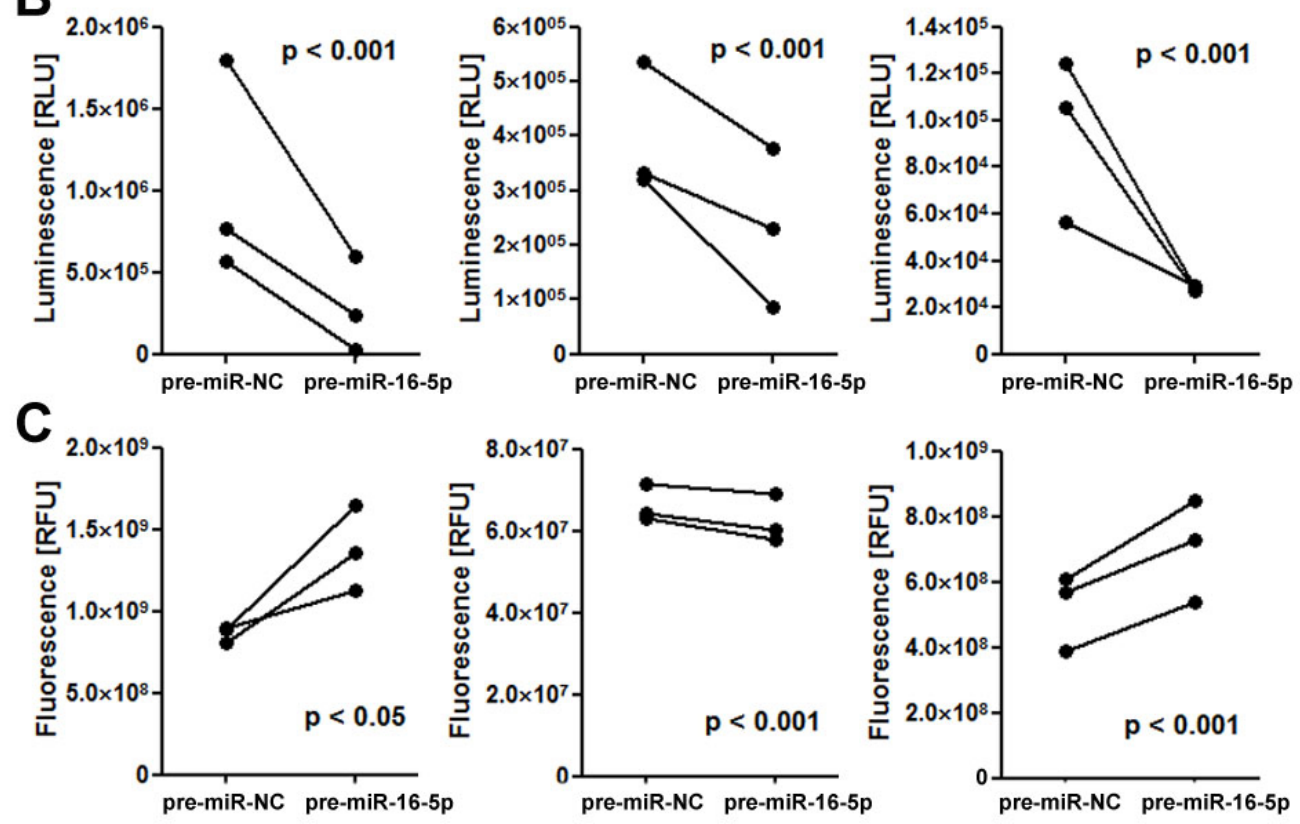

Figure 2. Decreased viability and proliferation as well as increased caspase-3/7 activity following overexpression of miR-16-5p in glioma cells. Glioma cells were transiently transfected with $25 \mathrm{nM}$ (viability and proliferation) or $50 \mathrm{nM}$ (caspase-3/7 activity) pre miR 16-5p or pre-miR-NC controls for 72 hours. Graphs depict cell viability (A), proliferation (B) and caspase-3/7 activity (C) for the cell lines A172, TP98G, and TP365MG. Dots represent the mean of 5 replicate measurements. Three independent experiments were performed per cell line. P-values are calculated using a mixed model. For calculations, the fixed variable was the transfection group and the random variable was the week of transfection. RLU, relative luminescence units; RFU, relative fluorescence units 

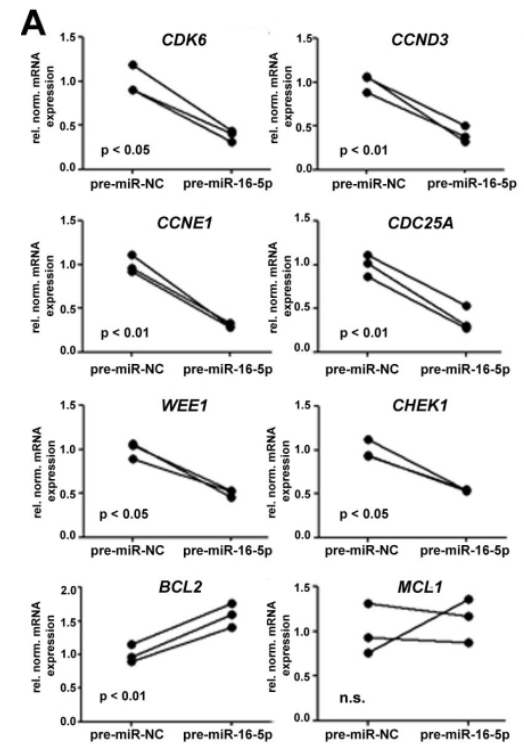
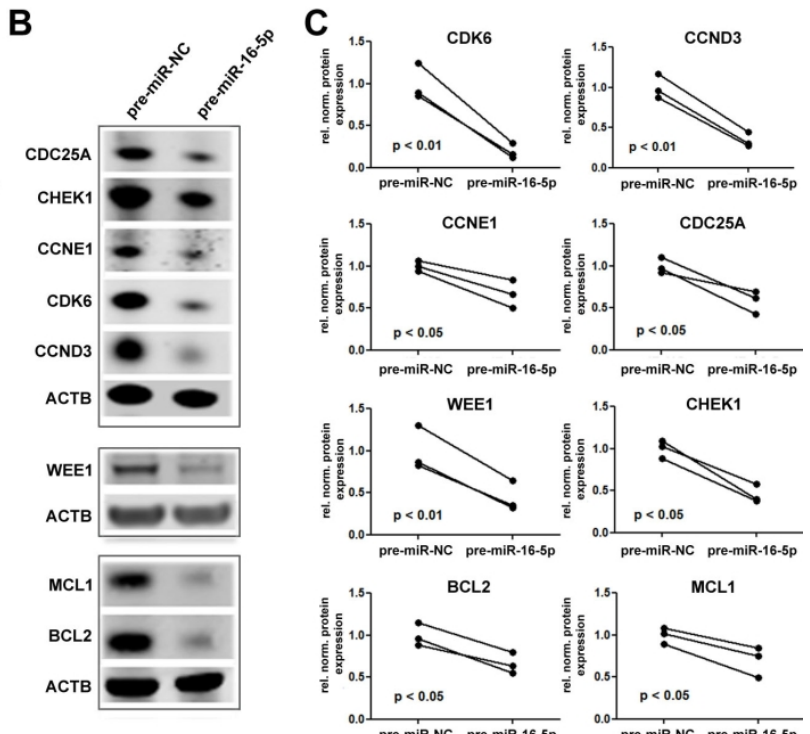

CHEK1
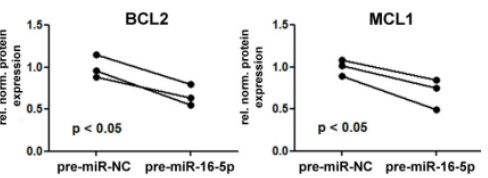

Figure 3. MRNA expression and protein levels of selected miR-16-5p target genes following transfection of miR-16-5p precursors in A172 glioma cells. (A) Shown are results of realtime-RT-PCR expression analyses using ARF1 as reference transcript. Three independent experiments were performed. P-values refer to twosided paired Student's t-tests. Note reduced expression of CDK6, CCND3, CCNE1, CDC25A, WEE1, and CHEK1 but not BCL2 and MCL1 transcripts after miR-16-5p overexpression. Exemplary results of Western blot analyses (B) and its quantifications (C) in A172 glioma cells transiently transfected with pre-miR-16-5p or pre-miR-NC are shown. Blots were immunostained for B-actin (ACTB) to normalize the protein levels in the individual lanes. Note that all eight target proteins, including BCL2 and MCL1, were down-regulated by miR-16-5p overexpression relative to control transfected cells $(B, C)$. 
A

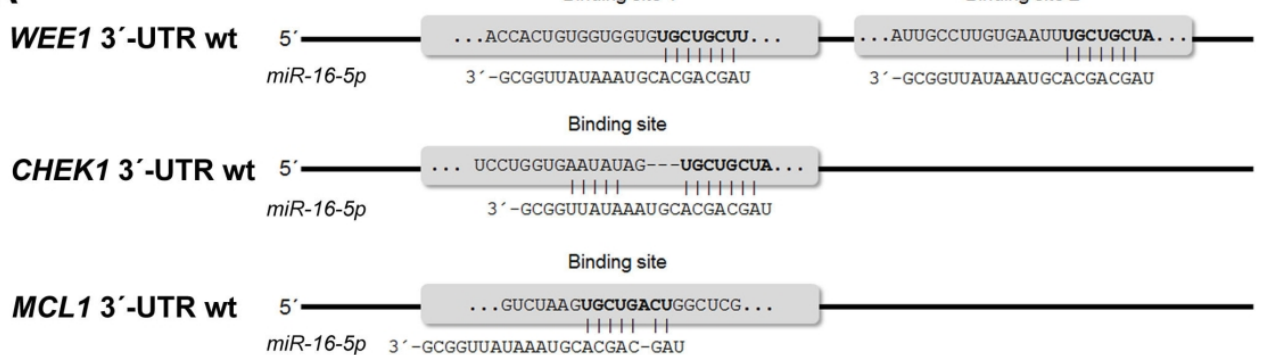

\section{B}
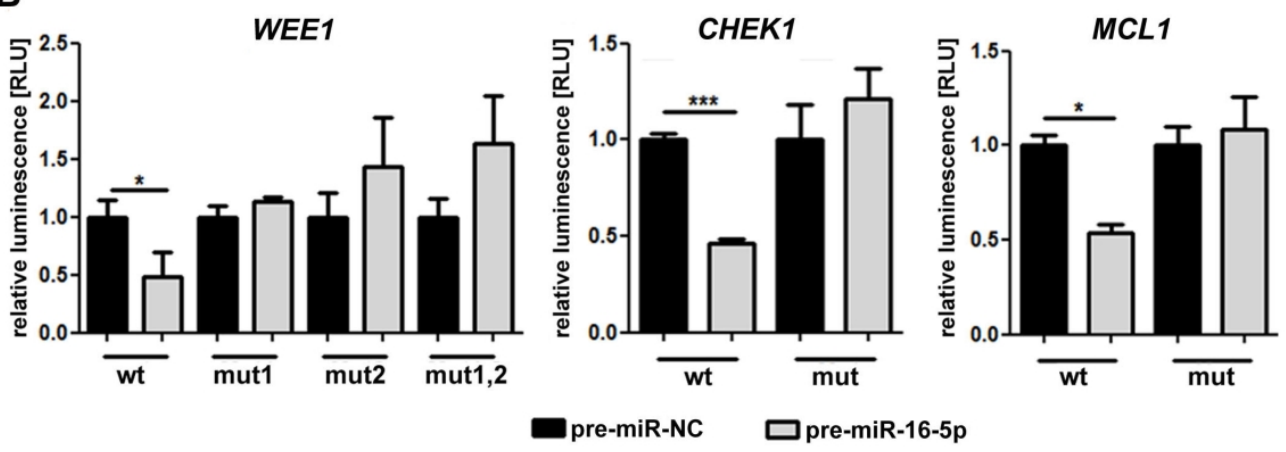

Figure 4. Demonstration of direct binding of miR-16-5p to the 3'-UTRs of WEE1, CHEK1, and MCL1 using luciferase reporter assay. (A) Schematic representation of miR $165 \mathrm{p}$ binding sites in the 3'-UTR of the target genes WEE1, CHEK1, MCL1 that were cloned into psiCHECK-2TM plasmids with flanking nucleotides.

Bold bases represent bases comprising the recognition sites for the miRNA seed sequence that were mutated (mut, mut1, mut2, mut1,2) to ensure specific miRNA binding. (B) T98G glioma cells were transiently co-transfected with either 100 ng WEE1, CHEK1 or MCL1 wildtype (wt) or mutated 3'-UTR reporter constructs and $50 \mathrm{nM}$ pre-miR-16-5p or pre-miR-NC for 72 hours (WEE1) or 48 hours (CHEK1 and MCL1). Bars and error bars represent the mean results of three independent experiments and standard errors of the mean. Each experiment comprised 5 replicates. P-values refer to two-sided, paired Student's t-tests $(*, \mathrm{p}<0.05 ; * * *, \mathrm{p}<0.001)$. RLU, relative luminescence units. 

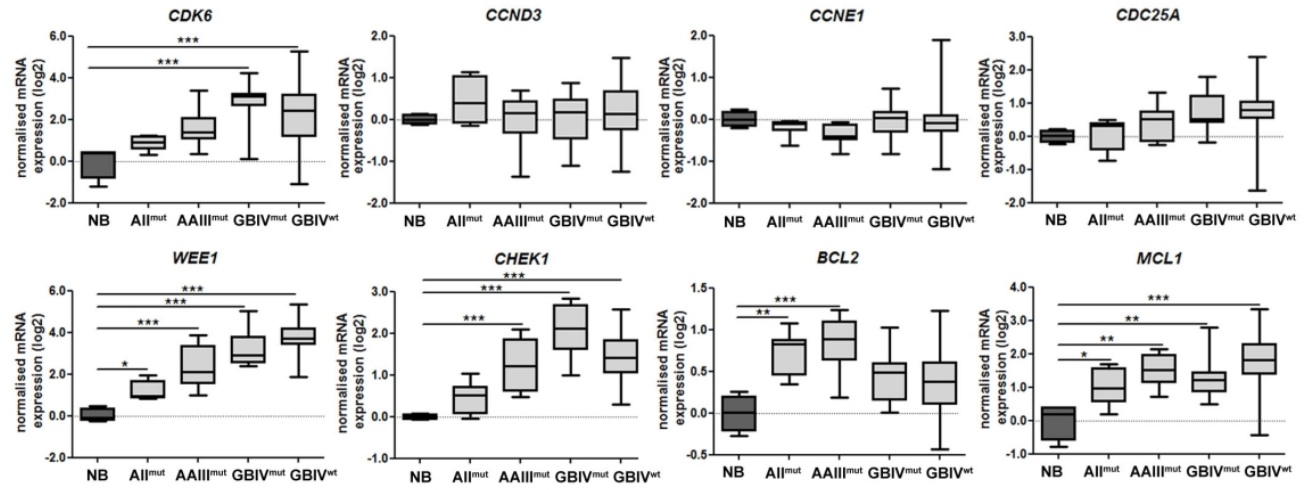

Figure 5. MRNA expression of several miR-16-5p target genes in gliomas. Results of microarray expression analyses of four non-neoplastic brain tissue (NB) and 68 human gliomas, including 8 AIImut, 10 AAIIImut, 11 GBIVmut, and 39 GBIVwt are shown. Box plots are depicted indicating median expression as well as lower and upper quartiles. Whiskers indicate lowest and highest expression values. Comparison between each tumour group and the non-neoplastic brain tissue group (NB) was performed by ANOVA and Dunnett's post hoc test. Asterisks indicate significant expression differences $(*, \mathrm{p}<0.05 ; * *, \mathrm{p}<0.01 ; * * *, \mathrm{p}<$ $0.001)$.

$180 \times 72 \mathrm{~mm}(300 \times 300 \mathrm{DPI})$ 

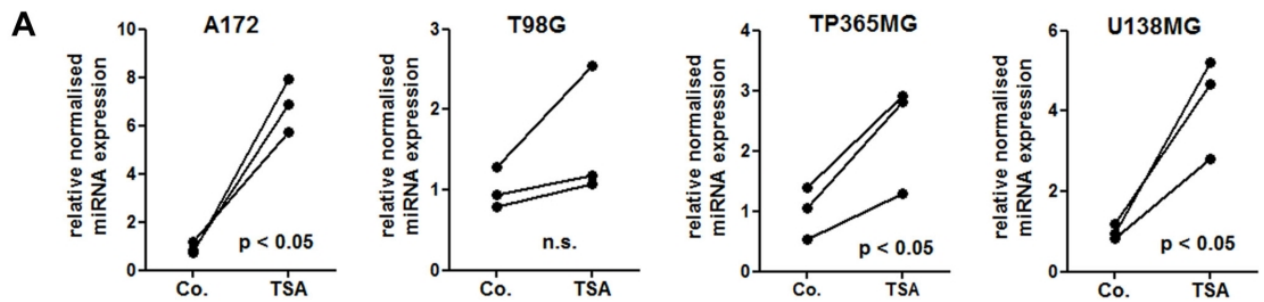

B

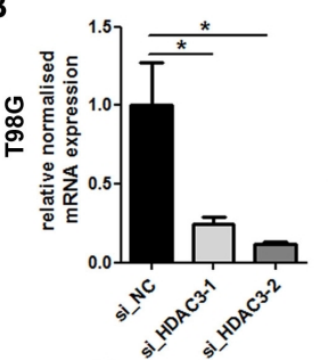

C
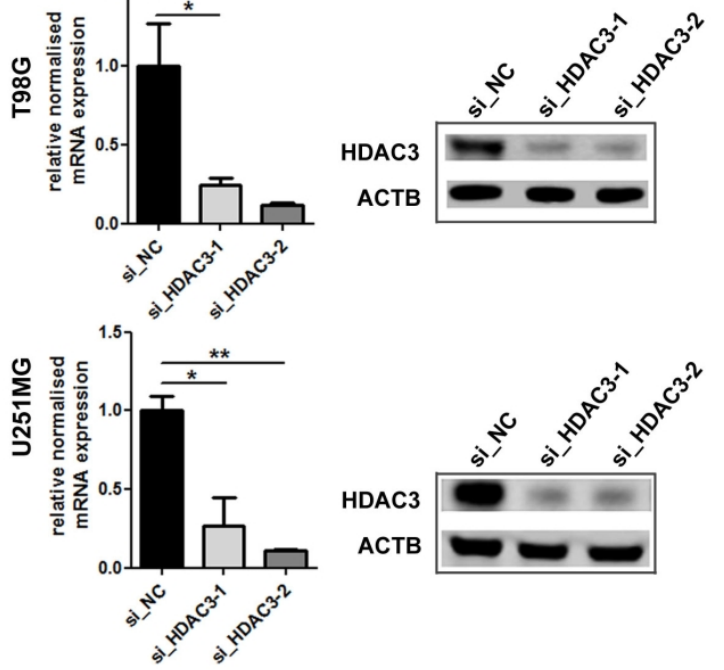

D

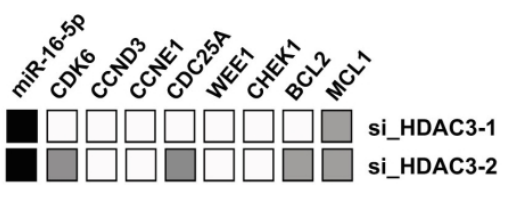

АСтB
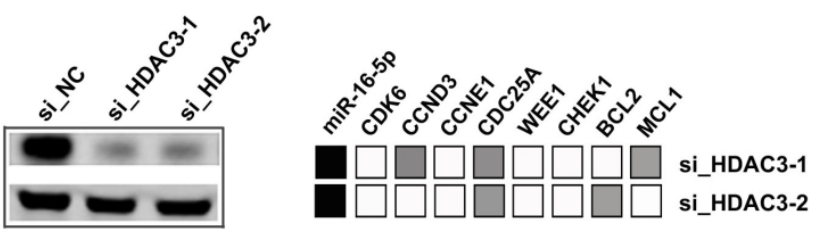

Figure 6. Treatment with trichostatin A (TSA) as well as siRNA-mediated HDAC3 knockdown increases miR16-5p expression in glioma cells. (A) Glioma cells were treated with $1 \mu M$ TSA for 36 hours. Shown are realtime RT-PCR results for miR-16-5p in A172, T98G, TP365MG, and U138MG cells. Each dot represents data from two technical replicates. Three independent experiments were performed. (B-D) Results of HDAC3 knockdown in T98G and U251MG glioma cells. Transfection of two siRNAs against HDAC3 (si_HDAC3-1, si_HDAC3-2) effectively reduced HDAC3 at the mRNA (B) and protein level (C) as compared to control transfected cells (si_NC). ARF1 was used to normalize mRNA expression and ACTB to normalize protein expression. HDAC3 knockdown resulted in significantly increased expression (black squares) of miR-16-5p as well as significantly reduced expression (white squares) of most of the investigated miR-16-5p target genes. Three independent transfections were performed. P-values were calculated using the two-sided, paired Student's t-test $(*, \mathrm{p}<0.05 ; * * \mathrm{p}<0.01)$. 

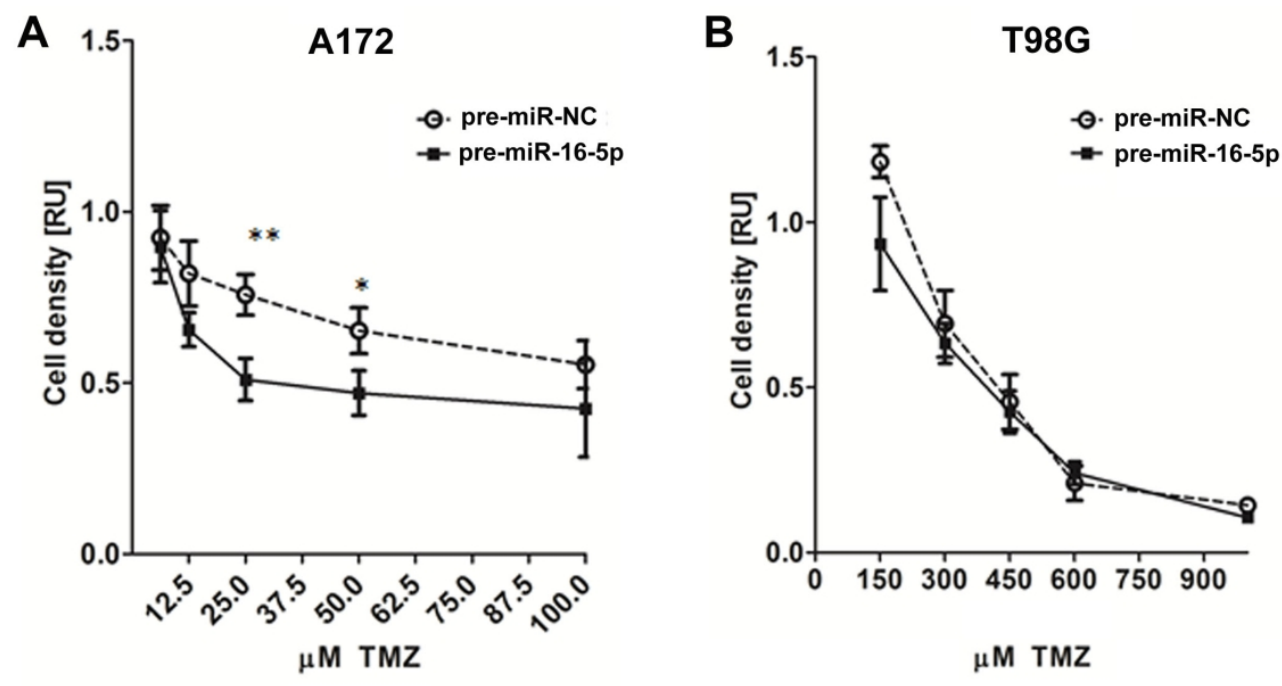

C

A172

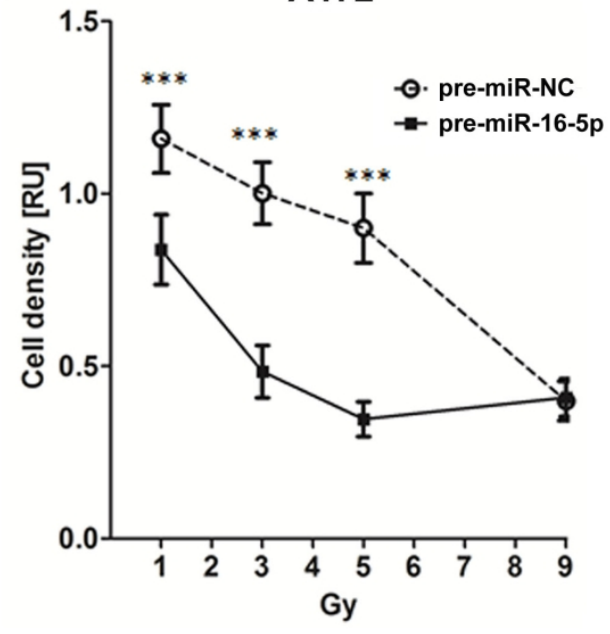

D

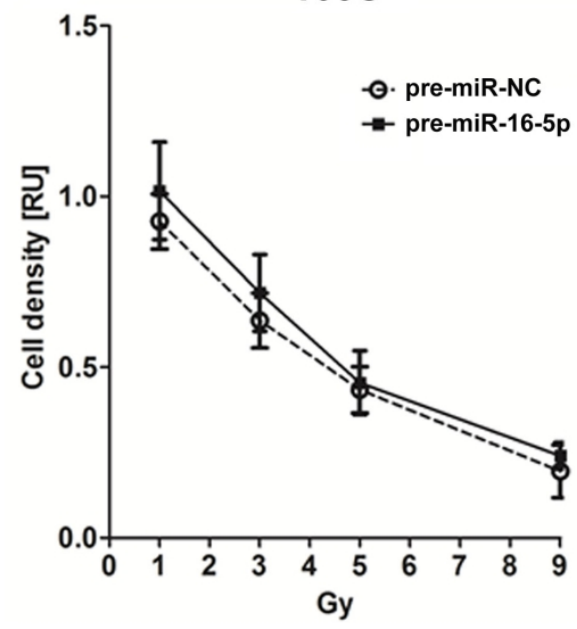

Figure 7. Modulation of glioma cell sensitivity to irradiation and temozolomide treatment by transfection of miR-16-5p precursors. Pre-miR-16-5p-transfected (black squares) or pre-miR-NC control-transfected (open circles) A172 cells $(A, C)$ or T98G cells $(B, D)$ were exposed to increasing concentrations of TMZ for $24 \mathrm{~h}$ ( $A$, $B$ ) or irradiated at increasing doses (C, D) and allowed to grow for 2-3 weeks in complete medium. Cell density was assessed by crystal violet staining. Data were assessed in triplets. Shown are diagrams of one of three independent replica experiments each $(*, \mathrm{p}<0.05 ; * *, \mathrm{p}<0.01 ; * * *, \mathrm{p}<0.001$, two-sided student's T-test). 
MiR-16-5p is frequently down-regulated in astrocytic gliomas and modulates glioma cell proliferation, apoptosis, and response to cytotoxic therapy

Anneliese Krell, ${ }^{1 \#}$ Marietta Wolter, ${ }^{1 \#}$ Nina Stojcheva, ${ }^{2}$ Caroline Hertler, ${ }^{2}$ Franziska Liesenberg, ${ }^{1}$ Marc Zapatka, ${ }^{3}$ Michael Weller, ${ }^{2}$ Bastian Malzkorn, ${ }^{1 *}$ Guido Reifenberger ${ }^{1,4 *}$

${ }^{1}$ Department of Neuropathology, Heinrich Heine University, Düsseldorf, Germany; ${ }^{2}$ Department of Neurology, University Hospital Zurich, Zurich, Switzerland; ${ }^{3}$ Division of Molecular Genetics, German Cancer Research Center, Heidelberg, Germany; ${ }^{4}$ German Cancer Consortium (DKTK), partner site Essen/Düsseldorf, DKFZ, Heidelberg, Germany

\section{Supplementary material}

Supplementary Table 1. Overview of primer sequences used for (1) qRT-PCR, $(2,3)$ luciferase reporter gene assay (2: with the wildtype binding sequence, and 3: with the mutated binding site for miR-16-5p). 


\begin{tabular}{|c|c|c|c|c|c|c|}
\hline Gene & Accession-No. & Chromosome & Primer sequence & Remarks & $\begin{array}{l}\text { Amplicon } \\
\text { length }\end{array}$ & Application \\
\hline CDK6 & NM_001259.6 & $7 \mathrm{q} 21.2$ & $\begin{array}{l}5 ' \text {-TGCACAGTGTCACGAACAGA } \\
\text { 5'-ACCTCGGAGAAGCTGAAACA }\end{array}$ & $\begin{array}{l}\text { forward } \\
\text { reverse }\end{array}$ & $150 \mathrm{bp}$ & 1 \\
\hline CCND3 & NM_001136017.3 & $6 \mathrm{p} 21.1$ & $\begin{array}{l}\text { 5'-CATGCCCAGACCTTTTTGGC } \\
\text { 5'-CAGTCCACTTCAGTGCCAGT }\end{array}$ & $\begin{array}{l}\text { forward } \\
\text { reverse }\end{array}$ & 176 bp & 1 \\
\hline CCNE1 & NM_001238.2 & $19 \mathrm{q} 12$ & $\begin{array}{l}\text { 5'-CAGATTGCAGAGCTGTTGGA } \\
\text { 5'-TCCCCGTCTCCCTTATAACC }\end{array}$ & $\begin{array}{l}\text { forward } \\
\text { reverse }\end{array}$ & 199 bp & 1 \\
\hline $\mathrm{CDC} 25 \mathrm{~A}$ & NM_001789.2 & $3 \mathrm{p} 21.31$ & $\begin{array}{l}\text { 5'-TGGCAAGCGTGTCATTGTTG } \\
\text { 5'-AGCTAGGGGGCTCACAGTAA }\end{array}$ & $\begin{array}{l}\text { forward } \\
\text { reverse }\end{array}$ & 194 bp & 1 \\
\hline \multirow[t]{2}{*}{ WEE1 } & \multirow[t]{2}{*}{ NM_001143976 } & \multirow[t]{2}{*}{$11 \mathrm{p} 15.4$} & $\begin{array}{l}\text { 5'-GAGTACTGCGCAGATGACCA } \\
\text { 5'-GAGGAGTCTGTCGCACATCA }\end{array}$ & $\begin{array}{l}\text { forward } \\
\text { reverse }\end{array}$ & $230 \mathrm{bp}$ & 1 \\
\hline & & & $\begin{array}{l}\text { 5'-gggtatctcgagGACAAGAGGAAGCTAGGTTG } \\
\text { 5'-ggctatgcggccgcAACACAAGTCAAAGACAAGTGC }\end{array}$ & $\begin{array}{l}\text { forward } \\
\text { reverse }\end{array}$ & 1075 bp & 2 \\
\hline \multirow[t]{3}{*}{ CHEK1 } & \multirow[t]{3}{*}{ NM_001114122.2 } & \multirow[t]{3}{*}{$11 \mathrm{q} 24.2$} & $\begin{array}{l}\text { 5'-TTACTGCAATGCTCGCTGGA } \\
\text { 5'-TGGGAGACTCTGACACACCA }\end{array}$ & $\begin{array}{l}\text { forward } \\
\text { reverse }\end{array}$ & 270 bp & 1 \\
\hline & & & $\begin{array}{l}5 \text { '-gggtatctcgagCTGGGGAATCCTGGTGAATAT } \\
5 \text { '-ggctatgcggccgcGTTTTGAAGCTGGCTTCGCT }\end{array}$ & $\begin{array}{l}\text { forward } \\
\text { reverse }\end{array}$ & 461 bp & 2 \\
\hline & & & $\begin{array}{l}\text { 5'-gggtatctcgagCTGGGGAATCCTGGTGAATATAGGTAG } \\
\text { TAGCTGTTGAC } \\
\text { 5'-ggctatgcggccgcGTTTTGAAGCTGGCTTCGCT }\end{array}$ & $\begin{array}{l}\text { forward } \\
\text { reverse }\end{array}$ & 461 bp & 3 \\
\hline BCL-2 & NM_001127240.2 & $19 \mathrm{q} 13.32$ & $\begin{array}{l}\text { 5'-GAGGATTGTGGCCTTCTTTG } \\
\text { 5'-ACAGTTCCACAAAGGCATCCCA }\end{array}$ & $\begin{array}{l}\text { forward } \\
\text { reverse }\end{array}$ & $170 \mathrm{bp}$ & 1 \\
\hline MCL-1 & NM_021960.4 & $1 \mathrm{q} 21.3$ & $\begin{array}{l}\text { 5'-TCTCTCGGTACCTTCGGGAG } \\
\text { 5'-AACCCATCCCAGCCTCTTTG }\end{array}$ & $\begin{array}{l}\text { forward } \\
\text { reverse }\end{array}$ & 400 bp & 1 \\
\hline HDAC3 & NM_003883.3 & $5 q 31.3$ & $\begin{array}{l}\text { 5'-GGAGCTGGACACCCTATGAA } \\
\text { 5'-GACTCTTGGTGAAGCCTTGC }\end{array}$ & $\begin{array}{l}\text { forward } \\
\text { reverse }\end{array}$ & 199 bp & 1 \\
\hline DLEU2 & NR_002612.1 & $13 \mathrm{q} 14.2$ & $\begin{array}{l}\text { 5'-GAGGGCAATAAATGCCACAT } \\
\text { 5'-GTGGTCCAGAAAACCTGCTC }\end{array}$ & $\begin{array}{l}\text { forward } \\
\text { reverse }\end{array}$ & 109 bp & 1 \\
\hline ARF1 & NM_001658.3 & $1 \mathrm{q} 42.13$ & $\begin{array}{l}\text { 5'-GACCACGATCCTCTACAAGC } \\
\text { 5'-TCCCACACAGTGAAGCTGATG }\end{array}$ & $\begin{array}{l}\text { forward } \\
\text { reverse }\end{array}$ & $111 \mathrm{bp}$ & 1 \\
\hline \multirow[t]{2}{*}{ B2M } & \multirow[t]{2}{*}{ NM_004048.2 } & \multirow[t]{2}{*}{$15 \mathrm{q} 21.1$} & $\begin{array}{l}\text { 5'-GTTGCTCCACAGGTAGCTCTAG } \\
\text { 5'-ACAAGCTTTGAGTGCAAGAGATTG }\end{array}$ & $\begin{array}{l}\text { forward } \\
\text { reverse }\end{array}$ & $123 \mathrm{bp}$ & 4 \\
\hline & & & $\begin{array}{l}\text { 5'-GTCTCGCTCCGTGGCCTTAG } \\
\text { 5'-CATTCTCTGCTGGATGACGTGAG }\end{array}$ & $\begin{array}{l}\text { forward } \\
\text { reverse }\end{array}$ & $110 \mathrm{bp}$ & 4 \\
\hline psiCHECK2 & plasmid & & $\begin{array}{l}\text { 5'-AGGACGCTCCAGATGAAAT } \\
\text { 5'-CAAACCCTAACCACCGCT }\end{array}$ & $\begin{array}{l}\text { forward } \\
\text { reverse }\end{array}$ & * & 5 \\
\hline
\end{tabular}


A tP365Mg mRnA B tP365Mg Protein C
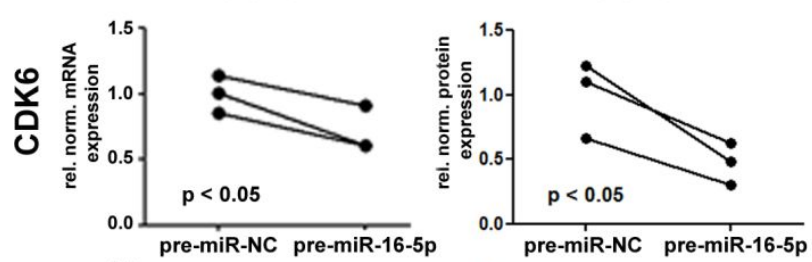

C U251MG mRNA

U251MG Protein
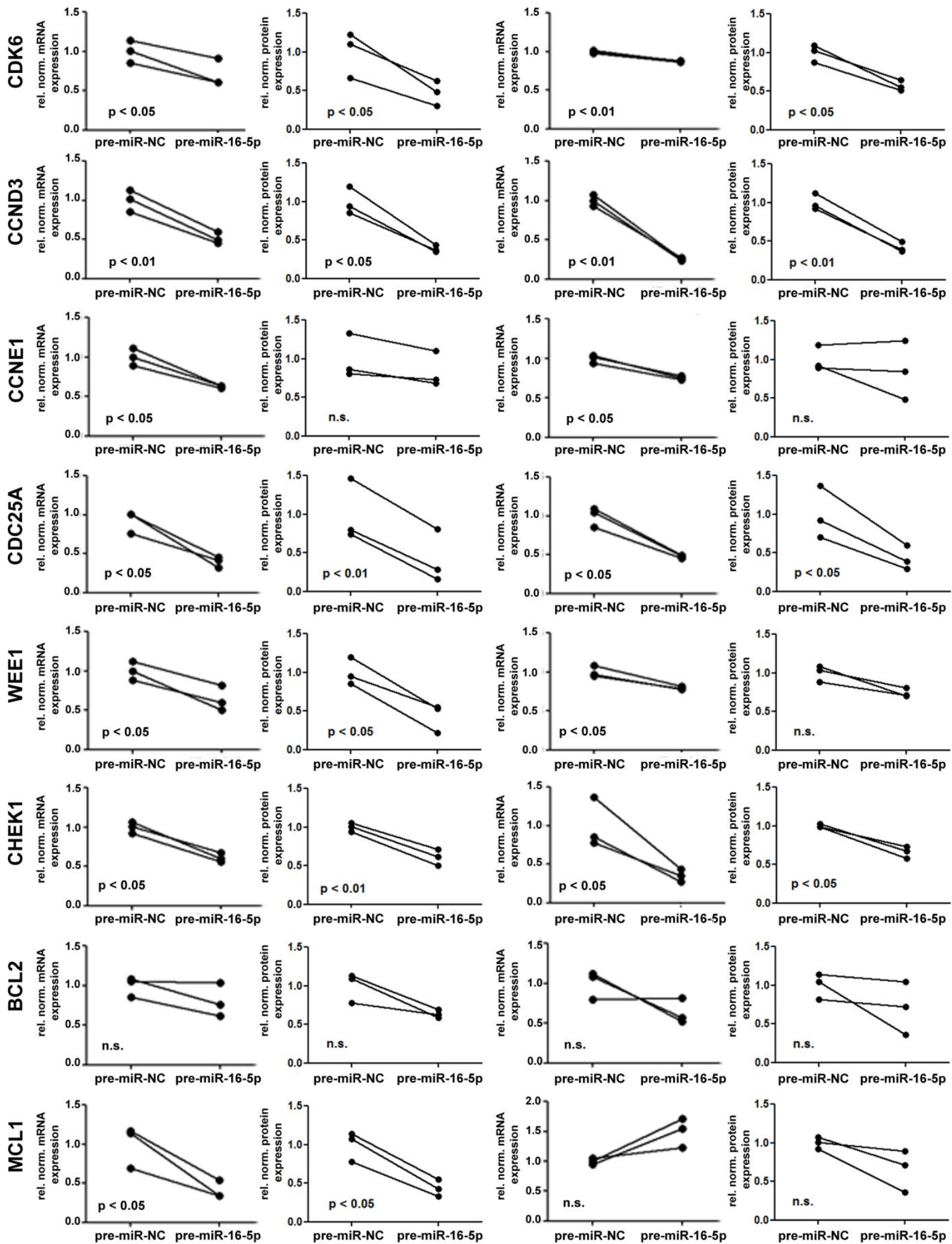

Supplementary Figure 1. Decreased expression of selected target genes following transfection of miR-16-5p precursors in TP365MG and U251MG glioma cells. (A, C) Results 
of qRT-PCR expression analyses using ARF1 as reference. Three independent experiments were performed. P-values refer to two-sided paired Student's t-tests. (B, D) Quantification of Western blot analyses. Blots were immunostained for beta-actin (ACTB) to normalize protein levels in the individual lanes. 
A

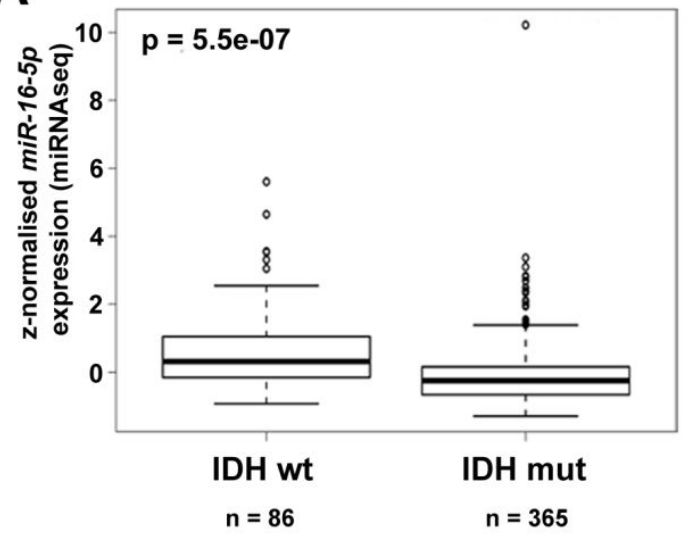

C

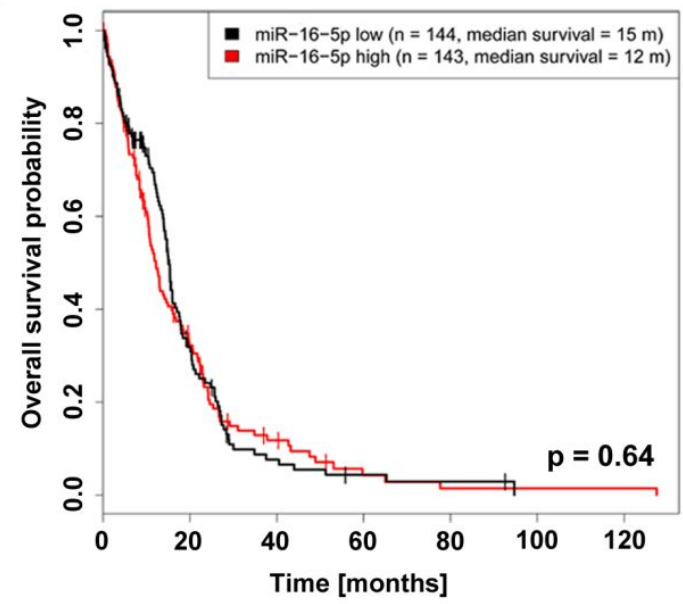

B

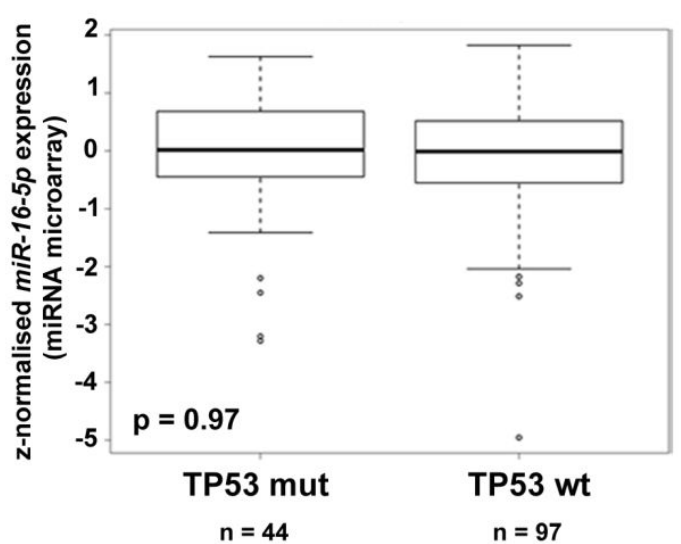

D

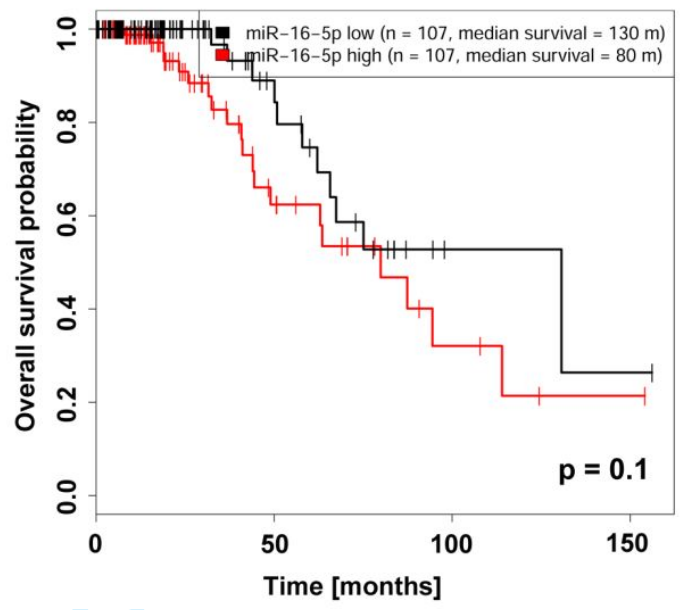

Supplementary Figure 2. Results based on correlative analyses of TCGA data sets, (A) Lower expression of miR-16-5p in IDH-mutant (IDH mut, $\mathrm{n}=365$ ) as compared to IDH-wildtype gliomas from the TCGA-LGG dataset (IDH wt, $n=86$ ). (B) MiR-16-5p expression does not differ between TP53-wildtype and TP53-mutant IDH-wildtype glioblastomas ( $\mathrm{n}=141)$. (C-D) MiR-16-5p expression is not linked to overall survival in IDH-wildtype glioblastoma patients $(n=287)$ (C) and in IDH-mutant diffuse and anaplastic astrocytoma patients $(n=214)(D)$. 

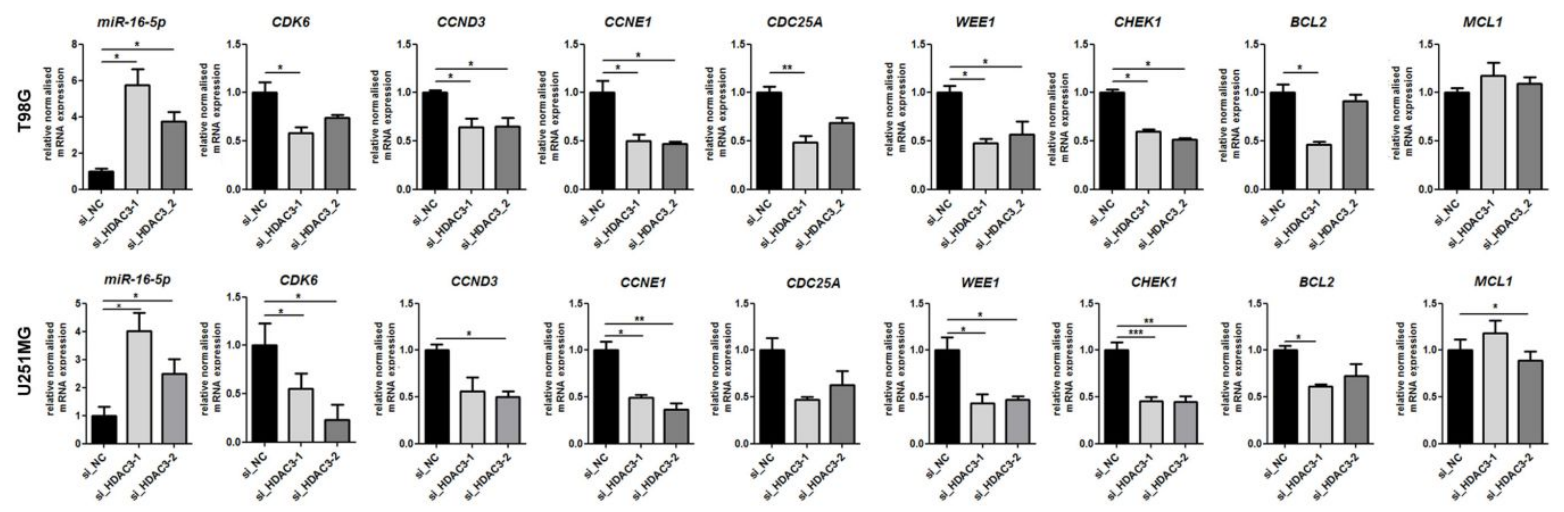

Supplementary Figure 3. Increased expression of miR-16-5p and reduced expression of its target genes in T98G and U251MG glioma cells following HDAC3 knock-down. Results of qRT-PCR using U6 snRNA as reference for miRNA expression analysis and ARF1 as reference gene for mRNA expression analysis in T98G or U251MG cells transiently transfected with $50 \mathrm{nM}$ siRNA against $H D A C 3$. Three independent experiments were performed. P-values refer to two-sided paired Student's t-tests. 